OPEN ACCESS

Edited by:

George Smith,

Temple University, United States

Reviewed by:

Gong Chen,

Jinan University, China

Bin Yu,

Nantong University, China

${ }^{*}$ Correspondence:

Carol Schuurmans cschuurm@sri.utoronto.ca

Received: 20 September 2020 Accepted: 31 December 2020

Published: 25 January 2021

Citation:

Balakrishnan A, Belfiore L, Chu T-H,

Fleming T, Midha R, Biernaskie J and Schuurmans C (2021) Insights Into the Role and Potential of Schwann Cells for Peripheral Nerve Repair From Studies of Development and Injury.

Front. Mol. Neurosci. 13:608442. doi: $10.3389 /$ fnmol.2020.608442

\section{Insights Into the Role and Potential of Schwann Cells for Peripheral Nerve Repair From Studies of Development and Injury}

\author{
Anjali Balakrishnan ${ }^{1,2}$, Lauren Belfiore ${ }^{1,3}$, Tak-Ho Chu ${ }^{4}$, Taylor Fleming ${ }^{1}$, Rajiv Midha ${ }^{4}$, \\ Jeff Biernaskie ${ }^{5}$ and Carol Schuurmans ${ }^{1,2,3 *}$
}

\begin{abstract}
'Biological Sciences Platform, Sunnybrook Research Institute (SRI), Toronto, ON, Canada, ${ }^{2}$ Department of Biochemistry, University of Toronto, Toronto, ON, Canada, ${ }^{3}$ Department of Laboratory Medicine and Pathobiology, University of Toronto, Toronto, ON, Canada, ${ }^{4}$ Department of Clinical Neurosciences, Hotchkiss Brain Institute, Cumming School of Medicine, University of Calgary, Calgary, AB, Canada, ${ }^{5}$ Department of Comparative Biology and Experimental Medicine, Hotchkiss Brain Institute, University of Calgary, Calgary, AB, Canada
\end{abstract}

Peripheral nerve injuries arising from trauma or disease can lead to sensory and motor deficits and neuropathic pain. Despite the purported ability of the peripheral nerve to self-repair, lifelong disability is common. New molecular and cellular insights have begun to reveal why the peripheral nerve has limited repair capacity. The peripheral nerve is primarily comprised of axons and Schwann cells, the supporting glial cells that produce myelin to facilitate the rapid conduction of electrical impulses. Schwann cells are required for successful nerve regeneration; they partially "de-differentiate" in response to injury, re-initiating the expression of developmental genes that support nerve repair. However, Schwann cell dysfunction, which occurs in chronic nerve injury, disease, and aging, limits their capacity to support endogenous repair, worsening patient outcomes. Cell replacement-based therapeutic approaches using exogenous Schwann cells could be curative, but not all Schwann cells have a "repair" phenotype, defined as the ability to promote axonal growth, maintain a proliferative phenotype, and remyelinate axons. Two cell replacement strategies are being championed for peripheral nerve repair: prospective isolation of "repair" Schwann cells for autologous cell transplants, which is hampered by supply challenges, and directed differentiation of pluripotent stem cells or lineage conversion of accessible somatic cells to induced Schwann cells, with the potential of "unlimited" supply. All approaches require a solid understanding of the molecular mechanisms guiding Schwann cell development and the repair phenotype, which we review herein. Together these studies provide essential context for current efforts to design glial cell-based therapies for peripheral nerve regeneration.

\footnotetext{
Keywords: repair Schwann cells, peripheral nerve injury, transcriptional regulators, directed reprogramming, nerve repair

Abbreviations: BMP, bone morphogenetic protein; CNS, central nervous system; ESCs, embryonic stem cells; HDAC, histone deacetylase; hESC, human embryonic stem cell; iSC, immature Schwann cell; iPSC, induced pluripotent stem cell; MBP, myelin basic protein; MPZ, myelin protein zero; MAG, myelin associated glycoprotein; Ngfr, nerve growth factor receptor; NCC, neural crest cell; NRG1, neuregulin 1; P, postnatal day; PNI, peripheral nerve injury; PNS, peripheral nervous system; SCP, Schwann cell precursor; SKP, skin-derived precursors; TF, transcription factor; TGF $\beta$, transforming growth factor $\beta$; VPA, valproic acid.
} 


\section{PERIPHERAL NERVE INJURY AND THE ROLE OF SCHWANN CELLS}

\section{Peripheral Nerve Injury and Current Therapeutic Strategies}

White matter tracts in the peripheral (PNS) and central (CNS) nervous systems are comprised of nerve fibers (axons) and myelin-producing glial support cells that insulate axons to facilitate the rapid conduction of electrical impulses. Glial support cells include Schwann cells in the PNS and oligodendrocytes in the CNS (Nave, 2010). White matter dysfunction disrupts the close contacts between these glial cells and their neuronal counterparts and is a common feature of several neurological conditions that impact the PNS (e.g., peripheral neuropathy, peripheral nerve injury) and CNS (e.g., traumatic spinal cord/brain injury, multiple sclerosis, stroke; Sarbu et al., 2016). These white matter diseases frequently impose chronic lifelong disabilities, with palliative and rehabilitative care as the only available options. Efforts to design curative therapies have centered on glial cell replacement strategies, an approach with wide applicability to several neurological diseases. Here, we focus on current developments in the use of Schwann cells for white matter repair in the PNS.

A common misconception is that because PNS axons can regrow (Huebner and Strittmatter, 2009), neuronal regeneration occurs in the PNS and repair-strategies are not required. The reality is that peripheral nerve injury (PNI) resulting from trauma or peripheral neuropathies frequently results in lifelong disability. Nearly 360,000 people in North America alone suffer from upper extremity PNI annually, resulting in $8,648,000$ restricted activity days and 4,916,000 bed/disability days per year (Kelsey et al., 1997). Recovery from PNI is often suboptimal and life-long functional impairment and neuropathic pain are common (Menorca et al., 2013). Autologous nerve grafting, which aims to fill the gap between the proximal and distal nerve, is the standard-of-care treatment for severed nerve injuries (Dellon and Mackinnon, 1988). However, autologous nerve grafting requires the harvesting of a healthy nerve, which can lead to donor-site morbidity, including chronic and debilitating neuropathic pain (Hilton et al., 2007). Moreover, nerve graft repair yields relatively poor results; only $25 \%$ of patients recover full motor function and only $3 \%$ regain full sensory function after median nerve repair (Kelsey et al., 1997). Much of the failure is due to poor engraftment between donor and recipient nerves and delayed surgical intervention, resulting in distal muscle atrophy and fibrosis (Kelsey et al., 1997).

Given the inability of the peripheral nerve to self-heal and the lack of effective interventions to aid repair, there is a growing need to develop new therapeutic approaches. One alternative is the use of nerve conduits, also called axon guidance channels, which facilitate axon growth within the lumen of a tube to bridge the nerve ends (Kemp et al., 2008, 2009). Nerve conduits aid axonal regrowth and are made of self-degrading biocompatible materials that elicit no or a negligible inflammatory response
(Ichihara et al., 2008). However, there are only a few reports of successful nerve repair using these conduits, with repair in humans typically limited to small digit nerves and outcomes similar to nerve autografts (Schlosshauer et al., 2006). Nerve conduits also compare poorly to autografts for the repair of "critical length" defects, in part due to the lack of cellular support within the conduit (Berrocal et al., 2013b). Nerve conduits may thus be better suited as a platform for the delivery of growthenhancing substrates, such as nerve and glial growth factors, small segments of peripheral nerve, and/or purified Schwann cells (Berrocal et al., 2013a; Shakhbazau et al., 2014; Kornfeld et al., 2016). Indeed, conduits containing autologous nervederived Schwann cells promote fast and more efficient nerve regeneration than nerve conduits alone (Hood et al., 2009). The major challenge, however, is finding an appropriate source of human Schwann cells for therapeutic applications. The role of Schwann cells in the repair process, and efforts to generate Schwann cells for PNI repair are reviewed herein.

\section{A Primer on Schwann Cells and Their Response to Peripheral Nerve Injury}

In myelinated nerves, myelin, which is comprised of layers of tightly compacted cell membranes, is laid down in internodal segments, which are interspersed with myelin-sparse regions known as nodes of Ranvier (Figure 1; Rasband and Peles, 2015). Schwann cells enwrap both myelinated and non-myelinated axons (Figure 1; Jessen, 2004). During development, Schwann cells that associate with axons greater than $1 \mu \mathrm{m}$ in diameter differentiate into myelinating Schwann cells (Snaidero and Simons, 2014; Salzer and Zalc, 2016), while those associated with smaller diameter axons ( $<1 \mu \mathrm{m}$; e.g., C-fiber nociceptors) become non-myelinating Schwann cells, also termed "Remak" cells (Griffin and Thompson, 2008; Harty and Monk, 2017). Remak cells ensheathe numerous axons together (Griffin and Thompson, 2008; Harty and Monk, 2017), whereas myelinating Schwann cells typically myelinate only a single axon segment, with a single axon myelinated by hundreds to thousands of Schwann cells depending on the total internodal length (Snaidero and Simons, 2014; Salzer and Zalc, 2016). Schwann cells also have additional developmental and physiological functions, including clustering of ion channels at the nodes of Ranvier (Poliak and Peles, 2003), promotion of neuronal survival (Davies, 1998), and regulation of axonal diameter (Cole et al., 1994). Here, we focus on the role that Schwann cells play in axonal repair post-PNI.

Under pathological conditions, Schwann cells are required to promote peripheral nerve regeneration and restoration of function (Jessen and Mirsky, 2019b; Nocera and Jacob, 2020; Stassart and Woodhoo, 2020). To understand the role of Schwann cells in repair, it is important to understand the injury response. PNI leads to sterile inflammation at the site of injury, and axonal degeneration occurs distal to the site through a process termed Wallerian degeneration, observed both in crush and transection injuries (Figure 2A; Gaudet et al., 2011). Post-injury, severed peripheral nerves remain intact for several days, even distal to the injury, but ultimately degenerate in both rodents (Miledi and Slater, 1970; Lubińska, 1982; Beirowski et al., 2005) and on a slightly 


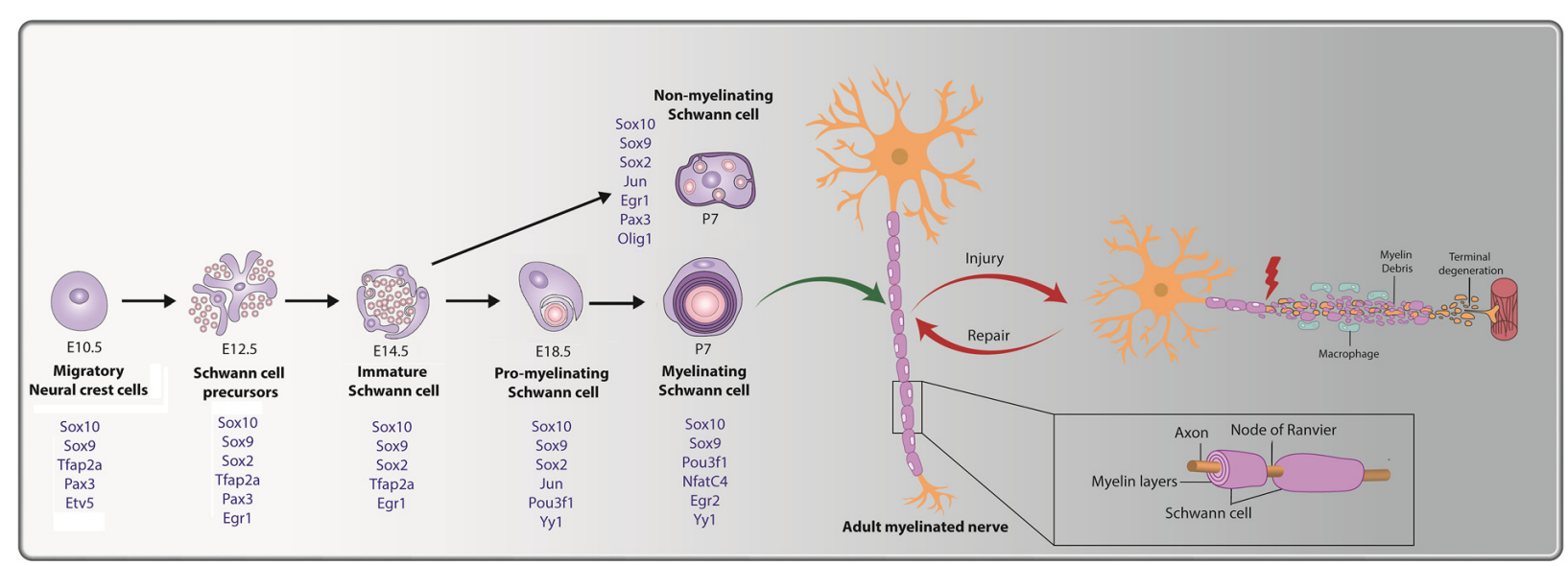

FIGURE 1 | Cellular transition steps during Schwann cell development and post peripheral nerve injury. Schwann cell development is marked by three transitory stages: (i) migratory NCCs (E10.5) fated towards a glial lineage generate Schwann cell precursors (SCPs) at E12.5, which associate with axons. (ii) SCPs give rise to immature Schwann cells (E14.5); and (iii) immature Schwann cells give rise to pro-myelinating Schwann cells (E18.5), which differentiate into mature myelinating or non-myelinating Schwann cells postnatally. Key transcription factors (TFs) and regulators of Schwann cell development that are expressed during the distinct stages are noted (in blue). The bottom inset presents a magnified view of a myelinating Schwann cell, with a myelin sheath deposited along the length of the axon. Nodes of Ranvier are observed at the meeting point of adjacent internodes. Peripheral nerve injury (PNI) leads to axonal degeneration resulting in axonal and myelin debris distal to the injury site. Schwann cells post-injury transition to a repair-like state and successfully repair and remyelinate the regenerated axon.

longer time course in humans (Chaudhry and Cornblath, 1992) and in non-human primates (Gilliatt and Hjorth, 1972). Axon degeneration occurs through calcium-mediated activation of calpains (Wang et al., 2004; Nikolaeva et al., 2005; Touma et al., 2007) and the proteasome (Zhai et al., 2003). As early as 2 days post-PNI, the site distal to the injury is riddled with neuronal and myelin ovoids (Figure 2A; Brosius Lutz et al., 2017). The injury site is also rapidly invaded by fibroblasts (Parrinello et al., 2010), inflammatory immune cells, including neutrophils, which are present transiently (Perkins and Tracey, 2000; Kennedy and DeLeo, 2009), and macrophages, the recruitment of which is stimulated by Schwann cell-secreted trophic factors, cytokines, and interleukins (Roberts et al., 2017).

Soon after PNI, due to loss of axonal contact, Schwann cells "de-differentiate" from a mature myelinating or non-myelinating state to a proliferating, precursor-like "repair" state (Figures 2A,B; Mirsky et al., 2008; Jessen and Mirsky, 2019a,b). While repair Schwann cells do not fully resemble a specific developmental stage at the molecular level, several developmental genes are re-expressed in repair Schwann cells post-injury, including transcription factors (TFs) that are critical regulators of development (e.g., Sox2, Oct6, and Jun; Balakrishnan et al., 2016). The idea that repair Schwann cells partially "de-differentiate" is also supported by the re-appearance of developmental phenotypes, including the re-initiation of proliferation and loss of myelination capacity. Indeed, Schwann cells downregulate myelin genes to inhibit myelin production distal to the injury site during the repair period (Arthur-Farraj et al., 2012; Jessen and Mirsky, 2016; Stratton et al., 2018). Moreover, repair Schwann cells participate actively in the removal of myelin fragments via autophagy/myelinophagy (Gomez-Sanchez et al., 2015), which is mediated by the phagocytic receptors Axl and Mertk (Brosius Lutz et al., 2017), and assisted by macrophage-mediated phagocytosis (Hirata and Kawabuchi, 2002; Jang et al., 2016; Brosius Lutz et al., 2017). Removal of myelin debris is essential as myelin creates a non-permissive environment for axons to re-grow (Hirata and Kawabuchi, 2002; Gomez-Sanchez et al., 2015; Brosius Lutz et al., 2017; Stratton et al., 2018).

Once myelin debris is cleared, the stage is set for axonal regrowth (Figure 2B). Together, Schwann cells and infiltrating macrophages secrete trophic factors and cytokines that promote axonal repair and regeneration (Chen et al., 2010; Fregnan et al., 2012; Shakhbazau et al., 2014; Johnston et al., 2016; Ko et al., 2018; Walsh et al., 2009). Macrophages also secrete VEGF-A to promote vascularization in the injury site, which aids the regeneration process (Cattin et al., 2015). Axonal sprouts from the proximal nerve stump emerge and slowly grow towards end-target organs, with the support of axonal guidance structures (or "regeneration tracks") consisting of basal lamina scaffolds, called Büngner bands (Figure 2B; Arthur-Farraj et al., 2012; Gomez-Sanchez et al., 2017; Chen et al., 2019). These bands are populated by proliferating repair Schwann cells that migrate in from both the proximal and distal nerve stump. Following axonal regeneration, repair Schwann cells each remyelinate a single axon, recapitulating the 1:1 association seen during development (Figure 2C; Gomez-Sanchez et al., 2017; Chen et al., 2019). Fbxw7, an E3 ubiquitin ligase expressed in Schwann cells, is an essential "gatekeeper" of re-myelination events post-injury, preventing the myelination of multiple axons (Harty et al., 2019). Notably, the hyper-myelinating phenotype of Fbxw7 mutant Schwann cells has led to speculation that knockdown of this gene could be used therapeutically in PNS 


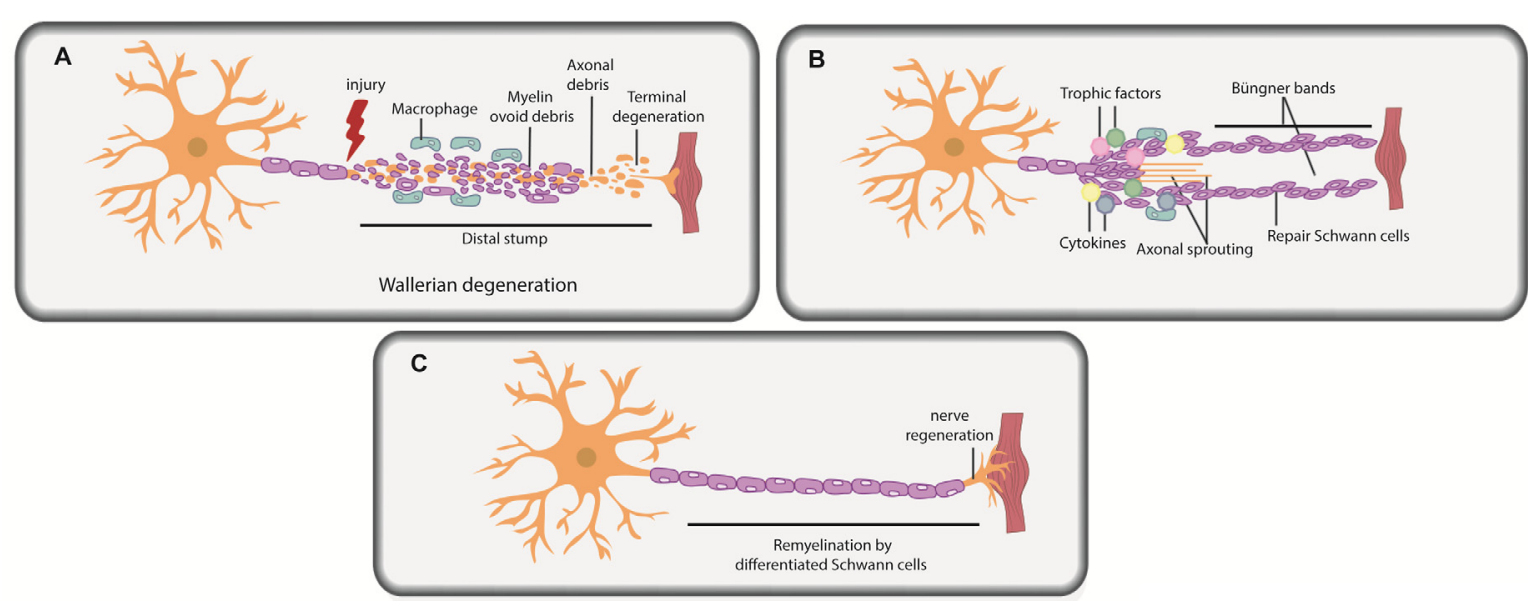

FIGURE 2 | Schwann cells in peripheral nerve repair. (A) PNI leads to axonal degeneration distal to the injury site through a process termed Wallerian degeneration. Axonal and myelin debris is observed in the distal stump. Repair Schwann cells proliferate, and an influx of macrophages and fibroblasts commences, leading to myelinophagy and macrophage-mediated phagocytosis of myelin debris. (B) Repair Schwann cells populate the distal stump and promote axonal regeneration and distal target tissue reinnervation. Trophic factors and cytokines secreted by repair Schwann cells and macrophages further promote axonal repair and regeneration. Basal lamina scaffolds deposited by repair Schwann cells form an axonal guidance structure called Büngner bands to support axonal regrowth and help direct correct target organ innervation. (C) Repair Schwann cells successfully myelinate the regenerated axon.

diseases, such as Charcot-Marie-Tooth disease, a demyelinating hereditary neuropathy (Murakami and Sunada, 2019), but the therapeutic potential of such an approach remains to be tested.

\section{Schwann Cell Potential for Glial Support Cell Therapy}

As time progresses post-injury, the repair-ability of Schwann cells declines, in part due to a loss of axonal communication as nerve fibers degenerate, halting any further functional recovery (Kelsey et al., 1997; Arthur-Farraj et al., 2012; Saheb-Al-Zamani et al., 2013; Kumar et al., 2016; Poppler et al., 2016; Hoben et al., 2018; Kornfeld et al., 2019; Wilcox et al., 2020). Schwann cells thus have a limited remyelination capacity in chronically denervated distal nerves. Moreover, given the long distances required for peripheral nerve regeneration in humans, and the relatively slow rate of axonal regrowth $(\sim 1 \mathrm{~mm}$ /day; Sunderland, 1947), PNIs often result in chronic denervation due to Schwann cell dysfunction, thus limiting functional outcomes for patients.

Advanced age also greatly diminishes nerve regenerative capacity (Painter et al., 2014; Scheib and Hoke, 2016; Buttner et al., 2018). Nerve grafts isolated from younger mice more potently promote nerve regeneration than nerve grafts from older mice (Painter et al., 2014; Scheib and Hoke, 2016; Buttner et al., 2018). Specifically, there is increased macrophage infiltration and Schwann cell phagocytosis in younger nerve grafts, while a hyperinflammatory response is observed in older nerve grafts post-injury (Painter et al., 2014; Scheib and Hoke, 2016; Buttner et al., 2018). A delay in expression of key regulators of a repair phenotype (e.g., Jun), as described further below, is also observed in aged Schwann cells (Chen et al., 2017). Additionally, Schwann cell survival, proliferation, differentiation, and myelination potential, all decline with age
(Liu et al., 2018). PNI repair may also be sexually dimorphic, with some reports demonstrating that females exhibit faster regeneration and remyelination post-injury (Kovacic et al., 2004; Magnaghi et al., 2006; Tong et al., 2015), whereas another study revealed more pronounced axonal outgrowth in males (Stenberg and Dahlin, 2014). Further research is thus required to elucidate the nature of any sex-based differences.

Given their role in the normal repair response, transplanted Schwann cells can support nerve repair. Indeed, enhanced functional recovery is observed when Schwann cells are transplanted in injured nerves in mice, rats, and nonhuman primates (Levi et al., 1994; Rodríguez et al., 2000; Berrocal et al., 2013a; Wakao et al., 2010). The first clinical use of autologous Schwann cells to supplement sciatic nerve autograft repair was reported in 2017 and strong motor function of the tibial nerve and partial restoration of sensation was observed in one patient (Gersey et al., 2017). However, Schwann cell transplants suffer from similar limitations as nerve grafting: the requirement for a nerve biopsy to isolate Schwann cells, as well as extended expansion time required to generate sufficient cell numbers for transplantation (Hood et al., 2009). Moreover, autologous Schwann cell transplantation strategies are further hampered by the limited proliferative capacity of adult nerve-derived Schwann cells in vitro, which senesce when grown ex vivo, and the greatly diminished regenerative capacity of Schwann cells derived from patients of advanced age (Painter et al., 2014; Weiss et al., 2016; Monje et al., 2018). Alternative sources of Schwann cells are thus being actively explored as a solution for transplant purposes (Woodhoo et al., 2007; Agudo et al., 2008).

\section{Future Perspectives}

Given the role of repair Schwann cells in remyelination postPNI, these cells are an ideal therapeutic target for future 
clinical strategies. However, more information is required if we are to fully exploit the power of glial cell replacement therapies, either by devising new strategies for the prospective isolation of endogenous "repair" Schwann cells or by engineering an exogenous source of these cells using lineage conversion strategies, as described later. Another important consideration is that Schwann cells derived from the skin, adult nerve, and embryo all differ in their proliferative, myelination, and repair capacity (Krause et al., 2014; Kumar et al., 2016), but whether these differences lie in population heterogeneity (i.e., different frequencies of Schwann cells with reparative potential within each population), or inherent differences in their myelinating and repair potential, is not known (Arthur-Farraj et al., 2012, 2017; Jessen and Mirsky, 2019b; Toma et al., 2020). If there are subsets of Schwann cells that carry inherent proliferative and/or survival advantages, they may be selected for post-transplant in vivo. The development of newer technologies to examine clonal behavior could be exploited to examine this possibility. For example, the clonal response of Schwann cells to injury could be monitored using a Cre reporter strategy [e.g., Brainbow mice (Baggiolini et al., 2015)] or with lentiviral libraries designed for cellular barcoding (Verovskaya et al., 2013). Indeed, the power of cellular barcoding has revealed differences in clonal selection between young and aged animals following hematopoietic stem cell transplant (Verovskaya et al., 2013) and could be applied to other transplant scenarios.

Another important line of future investigation would be the identification of biomarkers to prospectively isolate Schwann cells with a repair phenotype. Critical insights could be gleaned from single-cell RNA-sequencing to stratify Schwann cell populations, to identify genes encoding unique cell surface markers in those populations with a repair Schwann cell signature. Other possibilities include future analyses of Schwann cell surface proteomes to identify novel markers that may be used to identify and prospectively isolate repair Schwann cells.

\section{SCHWANN CELLS: UNDERSTANDING DEVELOPMENT TO ENGINEER REPAIR}

\section{A Synopsis of Embryonic Schwann Cell Development}

Schwann cells originate from migratory neural crest cells (NCCs) that emerge at the intersection between the neural and non-neural ectoderm and then undergo an epithelialto-mesenchymal transition before following distinct migratory paths, with pathway selection influencing final cell fates (Le Douarin and Dupin, 2003; Le Douarin et al., 2004; SaukaSpengler and Bronner-Fraser, 2008; Stuhlmiller and GarcíaCastro, 2012). NCCs that migrate through rostral somites become Schwann cells and boundary cap cells through a series of differentiation steps (Le Douarin and Kalcheim, 1999; Vermeren et al., 2003; Vega-Lopez et al., 2017). Boundary cap cells occupy the dorsal root entry zone and motor exit points in the embryonic spinal cord and give rise to Schwann cells occupying the spinal roots (Wilkinson et al., 1989; Niederlander and Lumsden, 1996; Vermeren et al., 2003; Maro et al., 2004; Coulpier et al., 2009).
Interestingly, boundary cap cells retain multipotency and can also give rise to oligodendrocytes when transplanted into the CNS (Zujovic et al., 2011).

Schwann cells that populate the spinal nerves are derived from NCCs that first give rise to Schwann cell precursors (SCPs), beginning at embryonic day (E) 12.5 in mouse (major differentiation steps outlined in Figure 1; Blanchard et al., 1996; Jessen and Mirsky, 2005, 2019a; Balakrishnan et al., 2016). Morphologically, SCPs are distinguished from NCCs as they lack a basal lamina and associate directly with growing axon bundles. SCPs are located proximal to the growing nerve tip, promote nerve compaction, and guide axons to their targets (Jessen and Mirsky, 2005, 2019a). As development proceeds, SCPs give rise to immature Schwann cells (iSCs) from E14.5 onwards, a cell type that persists up until birth (Jessen and Mirsky, 2005). Just before birth, individual iSCs contact a single axon, targeting only those larger diameter axons that produce higher levels of neuregulin 1 (NRG1; described further below; Feltri et al., 2015). The process by which iSCs select a single axon for myelination is called "radial sorting" (Feltri et al., 2015) and results in the conversion of iSCs to pro-myelinating Schwann cells, a transient population that ultimately become myelinating Schwann cells. In contrast, iSCs that pair with smaller diameter axon bundles, which release lower levels of NRG1, become non-myelinating (Remak) Schwann cells (Taveggia et al., 2005; Gomez-Sanchez et al., 2009).

\section{Key Transcription Factors Involved in Schwann Cell Development}

Several signatory transcription factors (TFs) are expressed during the transitory steps from NCC $\rightarrow$ SCP $\rightarrow$ iSC $\rightarrow$ pro-myelinating Schwann cell $\rightarrow$ myelinating/non-myelinating Schwann cell (summarized in Figure 1). As early as the NCC stage, glial cell fate determinants are expressed, including Sox9, Sox10, Tfap2a, Etv5, and Pax3 (Goulding et al., 1991; Kuhlbrodt et al., 1998; Hagedorn et al., 2000; Stewart et al., 2001; Cheung and Briscoe, 2003; Balakrishnan et al., 2016). When NCCs transition to SCPs, Sox9, Sox10, Tfap2a, and Pax3 continue to be expressed, and Sox2 and Egr1 expression is initiated, while Etv5 is downregulated (Topilko et al., 1997; Jessen and Mirsky, 2005; Balakrishnan et al., 2016; Jessen and Mirsky, 2019a). As SCPs become iSCs, transcription of the glial-TFs Sox9, Sox10, and Tfap $2 a$ persists, while SCP-specific TF Pax3 is turned off and Egr1 and Sox2 are downregulated (Topilko et al., 1997; Jessen and Mirsky, 2005; Balakrishnan et al., 2016; Jessen and Mirsky, 2019a). Next, iSCs convert to pro-myelinating Schwann cells that continue to express Sox9 and Sox10, downregulate Tfap2a, and begin to express the TFs Jun, Pou3f1, and Yy1 (Arroyo et al., 1998; He et al., 2010; Balakrishnan et al., 2016). Finally, myelinating Schwann cells continue to express Sox9, Sox10, Pou3f1, and Yy1 while also initiating the expression of Nfatc4, and Egr2 (Nagarajan et al., 2002; Kao et al., 2009; Balakrishnan et al., 2016). Notably, while Egr2 expression is not observed until late embryonic/early postnatal stages in Schwann cells lining the peripheral nerve, Egr2 is expressed in SCPs and Schwann cells populating the dorsal and ventral roots from E10.5 (Topilko et al., 1997; Maro et al., 2004; Balakrishnan et al., 2016). Egr1, which is downregulated at the SCP-to-iSC transition, is also re-expressed 
at postnatal stages, but only in non-myelinating Schwann cells, which transcribe Sox9, Sox10, Sox2, Jun, and Pax3 (Kioussi et al., 1995; Topilko et al., 1997; Yu et al., 2009; Blake and Ziman, 2013; Balakrishnan et al., 2016).

Loss- and gain-of-function studies have elucidated the roles of several of these signatory TFs in driving Schwann cell development and in the maintenance of a mature Schwann cell fate under normal physiological conditions.

(1) Sox (SRY-related HMG-box) genes: Sox9 and Sox10 are expressed throughout Schwann cell development, beginning in E10.5 NCCs and persisting in mature Schwann cells throughout life (Kuhlbrodt et al., 1998; Stewart et al., 2001; Cheung and Briscoe, 2003; Finzsch et al., 2010; Bremer et al., 2011; Balakrishnan et al., 2016). Surprisingly, the function of Sox9 in the Schwann cell lineage has yet to be elucidated to the best of our knowledge, in part because heterozygous mutants display perinatal lethality, and homozygous null mutants cannot be generated (Bi et al., 2001). While a floxed allele of Sox9 has been generated for conditional knock-out (cKO) purposes (Akiyama et al., 2002), they have not been used to assess Sox9 function in Schwann cell development.

During embryonic development, Sox10 is required for the generation of Schwann cells and satellite glia, which "cap" neuronal cell bodies in sensory ganglia (Paratore et al., 2001). At postnatal stages, Sox10 is not necessary for Schwann cell survival, as revealed by in vivo analyses of Sox 10 cKOs (Bremer et al., 2011), but Sox10 is required to maintain an intact and functional myelin sheath (Kim et al., 2003; Finzsch et al., 2010; Bremer et al., 2011), consistent with its role in transactivating genes involved in the generation of peripheral myelin (e.g., Egr2, MBP, MPZ, MAG, S100 $\beta$, Peirano et al., 2000; Bondurand et al., 2001; Ghislain and Charnay, 2006; Jones et al., 2007; LeBlanc et al., 2007; Fujiwara et al., 2014). Notably, Sox10 acts synergistically with other TFs to initiate a myelination program, including Pou3f1, Nfatc4 and Egr2 (Ghislain and Charnay, 2006; LeBlanc et al., 2006, 2007; Jang and Svaren, 2009; Kao et al., 2009; Jones et al., 2012).

Ectodermal cells that become NCCs upregulate Sox2 expression (Wakamatsu et al., 2004). As NCC development progresses, Sox2 expression declines in SCPs and iSCs, but maintaining low Sox2 levels is required to sustain a glial identity, whereas high Sox2 expression leads to neuronal commitment (Wakamatsu et al., 2004). Sox2 also controls a key decision point in SCPs, inhibiting the expression of Mitf so that SCPs differentiate into myelinating Schwann cells rather than melanocytes (Adameyko et al., 2012).

(2) Ets-domain gene (Etv5): Etv5 is expressed in NCCs and satellite glia, and then rapidly turns off in SCPs (Hagedorn et al., 2000; Balakrishnan et al., 2016). Etv5 loss-offunction studies using dominant-negative constructs in NCCs (Paratore et al., 2002) or hypomorphic mutants (Balakrishnan et al., 2020) did not reveal any defects in NCC glial fate selection or Schwann cell development, respectively. Interestingly, the related gene, Etv1, which is also expressed in Schwann cells (Srinivasan et al., 2007), is similarly not required for the development of myelinating Schwann cells (Fleming et al., 2016). However, Etv1 is required for peripheral axons to interact with non-myelinating Schwann cells in Pacinian corpuscles (Sedy et al., 2006; Fleming et al., 2016). One possibility is that Etv1 and Etv5 have redundant functions in the development of myelinating Schwann cells.

(3) AP-2 $\alpha$ (Tfap2a): Tfap $2 a$ is also expressed in NCCs, persists in SCPs, and then rapidly turns off in pro-myelinating Schwann cells (Balakrishnan et al., 2016; Jessen and Mirsky, 2019a). Sustained expression of Tfap2a in SCPs prevents the transition to iSCs, revealing that Tfap2a is a negative regulator of Schwann cell differentiation (Stewart et al., 2001).

(4) Pax3: Pax3 is also expressed in NCCs and turns off rapidly in SCPs before being re-expressed in Remak Schwann cells (Kioussi et al., 1995; Doddrell et al., 2012; Blake and Ziman, 2013). During development, Pax3 induces Schwann cell proliferation and blocks apoptosis (Nakazaki et al., 2009). When overexpressed in Schwann cells in vitro, Pax3 prevents Schwann cells from differentiating into myelinating cells by inhibiting $M B P$ and Egr2-driven $M P Z$ expression (Kioussi et al., 1995; Doddrell et al., 2012). Instead, Pax3 promotes a non-myelinating Schwann cell identity (Kioussi et al., 1995), consistent with its normal expression in Remak Schwann cells (Kioussi et al., 1995; Doddrell et al., 2012; Blake and Ziman, 2013).

(5) Pou3f1, Jun, Yy1: The expression of three key TFs is initiated in pro-myelinating Schwann cells: Pou3f1 (Arroyo et al., 1998), Nfatc4 (Kao et al., 2009), and Yy1 (He et al., 2010). Pou3f1, which is expressed in non-myelinating Schwann cells, turns off with the onset of myelination (Blanchard et al., 1996). However, Pou3f1 is required to induce Egr2 expression and initiate a myelination program, at least until postnatal day $(\mathrm{P})$ 10, when redundant programs take over, acting in synergy with Sox10 (Notterpek et al., 1999; Zorick et al., 1999; Ghazvini et al., 2002; Ghislain and Charnay, 2006). Pou3f1 overexpression leads to persistent hypo-myelination and gradual axonal loss by acting as a transcriptional repressor of $M B P$ and $M P Z$ (Monuki et al., 1993; Ryu et al., 2007). Pou3f1 thus has dual roles as a positive and negative regulator of myelination in the PNS.

Jun encodes a zinc finger TF that forms an AP1 heterodimeric complex with Fos (Abate and Curran, 1990). Jun is expressed in late iSCs at E17.5 and is then downregulated by Egr2 with the onset of myelination (Parkinson et al., 2004). Overexpression of Jun blocks myelination by suppressing Egr2 and MPZ expression, initiating a Schwann cell "de-differentiation" program (Parkinson et al., 2008). In contrast, Yy1 initiates Egr2 expression in a neuregulindependent manner and is a positive regulator of myelination (He et al., 2010).

(6) Egr1/Egr2: Egr1(Krox 24) and Egr2(Krox20) have opposing roles in myelination (Topilko et al., 1997). Activation of Egr2 initiates terminal differentiation of Schwann cells to a myelinating phenotype, turning on myelin-related genes such as $M B P, M P Z$, and $P m p 22$ (Nagarajan et al., 2002; LeBlanc et al., 2007; Jang and Svaren, 2009; Jones et al., 2012). Conversely, Egr1 is 
expressed in non-myelinating Schwann cells and drives a pro-proliferative phenotype (Topilko et al., 1997; Balakrishnan et al., 2016).

\section{Key Signaling Molecules Involved in Schwann Cell Development}

(1) Neurotrophins: nerve growth factor receptor (Ngfr), also known as p75NTR, is a low-affinity receptor for multiple neurotrophins. Ngfr is expressed in migrating NCCs and in developing Schwann cells throughout development but declines in expression as pro-myelinating Schwann cells mature to a myelinating state (Mirsky et al., 2008; Betters et al., 2010). In Ngfr knockouts, Schwann cells survive but fail to myelinate (Song et al., 2006). BDNF is a neurotrophin that is essential for iSCs to develop into myelinating Schwann cells, activating the expression of NFкB (Boyle et al., 2005). Stimulation of Ngfr in iSCs leads to nuclear translocation and activation of the NFאB subunit, p65, which initiates anti-apoptotic pathways to prevent Schwann cell death (Boyle et al., 2005). In the absence of NFкB (p65 knockout), iSCs undergo apoptosis due to a lack of survival signals from the axon (Boyle et al., 2005).

(2) Neuregulin signaling: neuregulins are axon-derived signaling proteins that are essential for Schwann cell development (Garratt et al., 2000). NRG1 exists in transmembrane and soluble isoforms, of which NRG1 type II and type III are relevant during Schwann cell development (Garratt et al., 2000; Falls, 2003). The survival and proliferation of SCPs depend upon transmembrane NRG1 type III, which binds to the receptor tyrosine kinases ErbB2 and ErbB3, both expressed by SCPs (Dong et al., 1995; Garratt et al., 2000). NRG1 type III is also essential during the terminal differentiation stage of Schwann cells to bring about successful myelination in vitro and in vivo (Michailov et al., 2004; Taveggia et al., 2005). Neuregulin signaling is dosage sensitive, with NRG1 type $\mathrm{III}^{+/-}$heterozygous neurons displaying axon ensheathment but poor myelination, a phenotype that can be rescued with low levels of exogenous NRG1 type III, whereas high levels inhibit myelination (Zanazzi et al., 2001; Syed et al., 2010).

Neuregulins intersect with several signal transduction pathways to mediate their effects. For instance, NRG1 type III activates PI3K/Akt signaling, which is essential for myelination (Taveggia et al., 2005). To achieve differentiation of Schwann cells in vitro, NRG1 type III, and high levels of cAMP are required, leading to CREB phosphorylation at Ser133 (Arthur-Farraj et al., 2011; Bacallao and Monje, 2015). Conversely, NRG1 acts as a Schwann cell mitogen when cAMP levels are low (Arthur-Farraj et al., 2011).

ErbB2 and ErbB3 also activate MEK-ERK signaling, which is required for Schwann cell differentiation, based on the analysis of ERK1/ERK2 mutants (Newbern et al., 2011). Conversely, if ERK signaling is ectopically activated in Schwann cells, myelination ensues (Ishii et al., 2013; Sheean et al., 2014). In contrast to NRG1 type III, soluble NRG1 type II isoforms signal in a paracrine fashion to inhibit myelination, an effect mediated by downstream MEK/ERK signaling, which promotes Jun expression-a known inhibitor of myelination (Syed et al., 2010; ArthurFarraj et al., 2012). The MEK/ERK pathway can block myelination alone as well as in cooperation with low levels of soluble NRG1 type II (Ogata et al., 2004; Chen et al., 2006; Syed et al., 2010). When MEK/ERK signaling is blocked, soluble NRG1 type II instead promotes myelination (Ogata et al., 2004). Critical TFs that are activated downstream of MEK-ERK are the Ets-domain proteins (Yang S. H. et al., 2013), including Pnt in Drosophila, which specifies a glial fate (Klaes et al., 1994), and Etv1, Etv4, and Etv5 in vertebrates. Notably, MEK-ERK initiates Etv1 and Etv5 to specify an oligodendrocyte fate in the CNS (Li et al., 2012; Wang et al., 2012; Li et al., 2014; Ahmad et al., 2019), but these factors are not required to specify a myelinating Schwann cell identity, as highlighted above.

(3) Hippo pathway: Yap and Taz, which are transcriptional co-activators and downstream effectors of the Hippo pathway, promote iSC proliferation, differentiation, myelination, and radial sorting (Lopez-Anido et al., 2016; Poitelon et al., 2016; Deng et al., 2017; Grove et al., 2017). Overexpression of Yap/Taz in naïve adult nerves leads to an increase in Schwann cell proliferation (Mindos et al., 2017; Wu et al., 2018). Yap/Taz initiate the expression of DNA binding proteins like Tead1 (Lopez-Anido et al., 2016), Cc2d1b, and Pur $\beta$ (Sophie et al., 2019) to promote Schwann cell proliferation and myelination.

(4) Wnts: canonical Wnt signaling induces Sox10 expression in NCCs (Honoré et al., 2003) and induces the expression of mature myelin genes such as MPZ and Pmp22 in Schwann cells (Tawk et al., 2011).

(5) Rho GTPases: small GTPases of the Rho (e.g., Cdc42, RhoA, Rac1) and Ras (RalA, RalB) families act as molecular switches, shuttling between activated GTP-bound and inactive GDP-bound states. Rho and Ras GTPases regulate cytoskeletal organization in Schwann cells to modulate critical events such as radial sorting during development (Benninger et al., 2007; Guo et al., 2013; Tan et al., 2018; Ommer et al., 2019). The chronic lack of Ral proteins in Schwann cells impairs radial sorting, resulting in the formation of unmyelinated or hypo-myelinated large-caliber axons, and abnormalities in the myelin sheath (Ommer et al., 2019). Similarly, the large GTPase Dynamin2 (Dnm2) is also required for Schwann cell survival, radial sorting, and myelination (Gerber et al., 2019). Deletion of Dnm2 in developing and/or adult Schwann cells leads to Schwann cell apoptosis, radial sorting impairment, and a demyelinating phenotype akin to defects seen in peripheral neuropathies (Gerber et al., 2019). 
(6) Bone morphogenetic proteins (BMPs): NCC are multipotent, giving rise to both glial and neuronal progeny. BMPs have neurogenic potential and direct a subset of NCCs towards the neuronal lineage during PNS development (Dore et al., 2009). BMP2 suppresses the expression of mature Schwann cell-specific genes in SCPs by inducing early-stage glial genes such as Gfap (Dore et al., 2009). SCPs residing in the cranial and trunk nerves are responsive to the neurogenic effects of $B M P 2$ and can switch between neuronal or glial fates, thereby giving rise to neurons in the parasympathetic ganglia (Dyachuk et al., 2014; Espinosa-Medina et al., 2014). Among the BMP subtypes, BMP7 is detected in early and adult postnatal sciatic nerves (Liu et al., 2016; Kokubu et al., 2018), and $B M P 7$ expression is associated with the suppression of the myelin gene (Pmp22, MBP, MPZ) expression (Liu et al., 2016).

\section{Future Perspectives}

While much is now known about the roles that individual TFs play in guiding Schwann cell development, it is important to note that none of these factors act in isolation-instead, TFs form complex gene regulatory networks (GRNs) that govern Schwann cell proliferation, myelination, and repair. Thus, while Sox10, Pou3f1, and Egr2 likely lie at the core of a myelinating GRN, given their importance in driving myelination (Jessen and Mirsky, 2019a), how Sox10, Pou3f1, and Egr2 act in a cooperative manner with the full complement of other TFs expressed in myelinating Schwann cells has not been fully elucidated.

In all tissues and organs, the selection of distinct cell fates during development occurs at lineage branch or decision points. The choice to follow one developmental fate or another is regulated by the combinatorial actions of TFs and chromatin structure, which defines the accessibility of TFs to their binding sites (Brand and Morrissey, 2020). Accordingly, Schwann cell development and myelination are also regulated by epigenetic drivers [reviewed in (Ma and Svaren, 2018; Duman et al., 2020)]. For instance, Schwann cells express histone deacetylase (HDAC) 1 and 2, which "open" chromatin to make it more accessible to binding by lineage-specifying TFs, as well as deacetylate TFs themselves to alter cellular activity (Jacob et al., 2011; ArthurFarraj et al., 2012). When overexpressed in Schwann cells, HDAC1 and 2 promote Sox 10 and MPZ expression, while lossof-function mutations prevent the expression of Sox10 and MPZ, leading to a hypomyelinating phenotype (Chen et al., 2011; Jacob et al., 2011; Brugger et al., 2015). It is thus important to consider how epigenetic drivers might influence the actions of TFs that act as lineage determinants and differentiation factors during Schwann cell development.

In the future, combinatorial analyses of transcriptomic and epigenomic data could be collected from progenitor cells at various stages in the Schwann cell differentiation program, allowing visualization of the GRNs that are associated with specific cell states (Okawa et al., 2015). Follow-up studies could then assess how these GRNs are influenced by extrinsic signals, for example, by examining how GRNs change in mutants that lack certain critical extrinsic signals, such as NRG1. Also, GRN studies could identify new TFs that lie at the center of regulatory hubs that may play critical roles in guiding Schwann cell developmental transitions.

\section{MOLECULAR REGULATORS OF THE SCHWANN CELL REPAIR RESPONSE}

Axonal injury in the periphery is followed by what some have termed Schwann cell "de-differentiation", which reverts mature myelinating Schwann cells to a "repair state" that resembles embryonic progenitor stages based on the re-initiation of expression of critical TFs and developmental signaling pathways (Balakrishnan et al., 2016; Jessen and Mirsky, 2019b). Also, repair Schwann cells express genes that are not normally expressed in the embryonic Schwann cell lineage, including the TF Olig1 and the signaling molecules GDNF, BDNF, and Shh, the repairspecific roles of which are reviewed below (Arthur-Farraj et al., 2012, 2017; Jessen and Mirsky, 2019b).

\section{Key Transcription Factors Involved in Schwann Cell Repair}

(1) Sox2: Sox2 is upregulated post nerve transection and is required for EphB/ephrin-B mediated clustering of Schwann cells at the injury site through re-localization of $\mathrm{N}$-cadherin to gap junctions (Parrinello et al., 2010). N-cadherin clustering in Schwann cells promotes the formation of multicellular cords (Büngner bands) responsible for guiding regenerating axons through the injured site (Parrinello et al., 2010). Sox2 expression also promotes infiltration of macrophages into the nerve, which are required to clear myelin and axonal debris from the site of injury (Roberts et al., 2017). Moreover, sustained expression of Sox 2 blocks myelination post-injury, and attenuates functional recovery (Roberts et al., 2017). However, the transcriptional targets of Sox 2 which are responsible for driving the Schwann cell response to injury are not yet known.

(2) Egr1/Egr2: Egr2 is rapidly downregulated in Schwann cells post-PNI, which aids in the reduction of myelin gene expression (Zorick et al., 1996; Topilko et al., 1997). In contrast, Egr1 expression is upregulated in Schwann cells post-injury, mimicking embryonic SCPs, and further highlighting the importance of Egrl in attaining a proliferative repair Schwann cell phenotype (Topilko et al., 1997).

(3) Jun: Jun is up-regulated post-PNI, and as an essential inhibitor of myelination, Jun has been aptly deemed a master regulator of nerve repair (Parkinson et al., 2004, 2008; Arthur-Farraj et al., 2012; Painter et al., 2014; Jessen and Mirsky, 2019b). Overexpression of Jun suppresses myelination and induces Schwann cell de-differentiation by suppressing myelination genes, such as Egr2 and MPZ (Parkinson et al., 2004, 2008; Arthur-Farraj et al., 2012; Painter et al., 2014; Jessen and Mirsky, 2019a). Jun also contributes to the clearance of myelin debris post-injury, which is crucial for successful nerve regeneration (Arthur- 
Farraj et al., 2012; Painter et al., 2014; Fazal et al., 2017). Finally, Jun also has non-cell-autonomous effects on motor neuron survival and axonal regeneration, as it is required to promote the expression of GDNF and other neurotrophic factors in Schwann cells (Fontana et al., 2012).

(4) Olig1: Olig1 is best known for its role in the differentiation of oligodendrocyte precursor cells in the CNS (Zhou et al., 2000). However, Olig1 is also expressed in P7 Remak cells, in adult sciatic nerves (Schmid et al., 2014), and is upregulated in the peripheral nerve post-injury (Arthur-Farraj et al., 2012). However, the function of Olig1 in repair Schwann cells is yet to be elucidated.

(5) Pax3: Pax3 is also upregulated in repair Schwann cells post-injury (Kioussi et al., 1995; Blake and Ziman, 2013). Since Pax3 promotes Schwann cell proliferation and prevents TGF $\beta$-mediated apoptosis (Nakazaki et al., 2009), Pax3 may play an important role in guiding Schwann cell dedifferentiation, but this possibility remains to be tested.

\section{Key Signaling Molecules Involved in Schwann Cell Repair}

(1) Neurotrophins: $N g f r$ is upregulated post-PNI, but promotes cell death, as revealed by the enhanced survival of Schwann cells in Ngfr KOs after injury (Hall et al., 1997; Ferri and Bisby, 1999). When Ngfr is activated by ligand binding, it promotes Schwann cell death when the RIP2 adaptor protein is bound to the Ngfr "death domain" (Khursigara et al., 2001). The pro-apoptotic functions of Ngfr post-PNI contrast to the essential role of $\mathrm{Ngfr}$ during myelination in development (Cosgaya et al., 2002). However, conventional Ngfr KOs deleted the gene in all cells, including both sensory neurons and Schwann cells in the peripheral nerve (Cosgaya et al., 2002). A more recent analysis of Schwann cell-specific Ngfr cKOs revealed that axonal repair and remyelination ability is intact post-PNI, suggesting that $N g f r$ is not required for repair (Gonçalves et al., 2019). Nevertheless, neurotrophic factors such as BDNF and GDNF are upregulated in Schwann cells post-injury and generally have anti-apoptotic effects that may instead be mediated by the Trk receptors (Funakoshi et al., 1993; Hoke et al., 2000). For instance, BDNF aids axonal regeneration by promoting neuronal survival (Boyd and Gordon, 2003), while GDNF supports the proliferation of Remak cells and ultimately the myelination of small, unmyelinated axons (Höke et al., 2003).

(2) Hippo pathway: Yap/Taz expression is upregulated in repair Schwann cells post-PNI, but declines with axonal degeneration (Grove et al., 2020). Repair Schwann cells can proliferate in the absence of Yap/Taz, but these genes are required for remyelination of injured nerves (Mindos et al., 2017; Wu et al., 2018; Grove et al., 2020).

(3) Bone morphogenetic proteins (BMPs): BMP7 is upregulated post-PNI, but there is a delayed response, with the increase in $B M P 7$ transcripts only observed after $24 \mathrm{~h}$, when myelination gene expression starts to decline (Liu et al., 2016). Consistent with BMP7 inhibiting myelination, the addition of BMP7 to Schwann cells in vitro reduces the expression of myelination- associated genes such as Pmp22 and Egr2 (Liu et al., 2016). Thus, BMP7 may help to attenuate myelination during the initial repair response post-PNI (Liu et al., 2016).

(4) Sonic hedgehog (Shh): Gli3 functions as a repressor of Hedgehog signaling in mature Schwann cells (Yamada et al., 2020). PNI reduces Gli3 expression, accompanied by increased Shh expression in repair Schwann cells, which promotes nerve regeneration (Yamada et al., 2020). Notably, Shh signaling induces Olig1 expression in myelinating oligodendrocytes in the CNS (Lu et al., 2000), and may thus underlie the observed increase in Olig1 expression in repair Schwann cells in the PNS.

(5) Growth factors: FGF2 is expressed in adult nerves and is upregulated post-PNI (Grothe et al., 2001). FGF2 promotes Schwann cell proliferation in vitro as well as in injured nerves in vivo. Schwann cells modified to overexpress FGF2 promote motor axon regeneration in a resected nerve model (Allodi et al., 2014). PDGF-AA is also secreted by Schwann cells post-nerve injury, and while PDGF is a known Schwann cell mitogen in vitro (Davis and Stroobant, 1990; Hardy et al., 1992), PDGF-AA also has paracrine effects, promoting the proliferation of mesenchymal cells during digit tip regeneration (Johnston et al., 2016).

(6) EphB/ephrin-B signaling: Activation of EphB/ephrin-B signaling is observed in Schwann cells in transection injuries of the peripheral nerve (Parrinello et al., 2010). When added to Schwann cell cultures, ephrin-B ligands induce clustering of these cells and segregation from fibroblasts that also fill the injury site (Parrinello et al., 2010). Ephrin-B mediated sorting of Schwann cells leads to the formation of multicellular cords that are essential for axonal regrowth across the injured site.

(7) Signal transduction cascades: several signal transduction cascades are activated in repair Schwann cells (reviewed extensively in Nocera and Jacob, 2020; Stassart and Woodhoo, 2020), including ERK1/2 (Sheu et al., 2000; Harrisingh et al., 2004; Hausott and Klimaschewski, 2019), Jun N-terminal Kinase (JNK; Parkinson et al., 2008; Monje et al., 2010), and p38 MAPK (Haines et al., 2008; Yang et al., 2012) signaling. JNK activation leads to phosphorylation of Jun, induces Schwann cell proliferation, and inhibits myelination (Parkinson et al., 2004, 2008; Monje et al., 2010). Similarly, p38 MAPK activity induces Jun expression, inhibits myelination, and promotes repair Schwann cells to associate with regrowing axons (Haines et al., 2008; Yang et al., 2012). Strikingly, sustained activation of MAPK signaling in developing Schwann cells leads to premature and continuous myelin synthesis, culminating in a hyper-myelinating phenotype (Sheean et al., 2014). However, MAPK activation is detrimental in mature Schwann cells, leading to myelin compaction defects and impaired formation of non-myelinating Schwann cell bundles (Cervellini et al., 2018), and is thus not useful as a therapeutic strategy. Similarly, while ERK1/2 activation induces Schwann cell de-differentiation at the site of injury (Sheu et al., 2000; Harrisingh et al., 2004), upregulation of ERK1/2 in Schwann cells under normal physiological 
conditions promotes a transient demyelinating phenotype (Napoli et al., 2012).

\section{Future Perspectives}

While recent studies have identified genes enriched in repair Schwann cells, a more detailed analysis of the repair Schwann cell phenotype will be gained by exploiting the power of single-cell transcriptomics (like in Toma et al., 2020) for population stratification and gene discovery. The information gained through such approaches may aid in the prospective isolation of a homogenous pool of "repair" cells for therapeutic purposes. Additionally, the further investigation of genes regulated by TFs like Olig1, which are exclusively expressed in repair Schwann cells, may also help to elucidate further insights into a repair Schwann cell phenotype.

An interesting question in the field of PNI repair is the variability in the repair response in humans vs. rodent models, which are commonly used in research (Meyer $\mathrm{Zu}$ Reckendorf et al., 2020). While the repair response is largely conserved between the two species, the transition of differentiated mature Schwann cells into proliferative repair cells is more robust in mice compared to humans (Meyer $\mathrm{Zu}$ Reckendorf et al., 2020). The enhanced repair response in mice is attributed to lower lipogenic gene expression and reduced S1P-PPAR $\gamma$ signaling, which prevents de novo myelin synthesis to promote nerve repair (Meyer $\mathrm{Zu}$ Reckendorf et al., 2020). Mimicking the murine response might prove beneficial for promoting a more pronounced repair response in humans post-injury. Given that PPAR $\gamma$ antagonist (SR16832, GW6992) administration in humans reduces lipogenic gene expression (Meyer $\mathrm{Zu}$ Reckendorf et al., 2020), such an approach could potentially aid PNI repair, perhaps in combination with growth factors to promote Schwann cell proliferation.

While the delivery of growth factors using novel systems (e.g., carriers like magnetic nanoparticles; Giannaccini et al., 2017) are in development, there is a possibility of adverse effects arising due to the administration of growth factors. For example, administration of FGF9 to a nerve injury led to fibrotic scar formation (Huang et al., 2020) and prevented Schwann cell de-differentiation ( $\mathrm{Lv}$ et al., 2019). Hence, it is important to assess the effects of exogenously administered growth factors carefully. In the future, the administration of appropriate growth factors/pharmacological agents in combination with exogenous Schwann cells may prove beneficial in promoting nerve repair.

\section{CELLULAR REPROGRAMMING FOR PERIPHERAL NERVE REPAIR}

\section{Directed Differentiation of Pluripotent and Somatic Stem Cells to Schwann Cells}

To use Schwann cells clinically, it is necessary to culture these cells on a large scale in vitro. In experimental animals, the sciatic nerve is a common source for harvesting and culturing Schwann cells (Morrissey et al., 1991). However, nerve-derived Schwann cells are not readily accessible (Hood et al., 2009), and to acquire large numbers of cells, long expansion periods are required (Morrissey et al., 1991). Given these limitations, nerve-derived Schwann cells are not an ideal source for experimental procedures or clinical applications (Faroni et al., 2016). Hence, alternative Schwann cell sources are required for the future development of glial support cell therapies (Figure 3).

Numerous groups have used small molecules and growth factors to derive Schwann cells from pluripotent or somatic stem cells, including skin-derived neural crest stem cells (Sakaue and Sieber-Blum, 2015), hair follicle-derived neural crest stem cells (Lavasani et al., 2014), muscle-derived stem/progenitor cells (Lavasani et al., 2014), dental pulp stem cells (Martens et al., 2014), umbilical cord- or bone marrow-derived mesenchymal stromal cells (Matsuse et al., 2010; Cai et al., 2017), adipose tissuederived stem cells (Faroni et al., 2016; Huang et al., 2020), human embryonic stem cells (hESCs; Ziegler et al., 2011; Liu et al., 2012), and induced pluripotent stem cells (iPSCs; Liu et al., 2012; Kim et al., 2017). These directed differentiation strategies take advantage of our knowledge of developmental processes, with two representative examples described.

(1) Directed differentiation of pluripotent stem cells: hESCs cultured as neurospheres in "Schwann cell differentiation media" containing NRG1 and forskolin, an adenylyl cyclase and protein kinase A agonist, differentiate into mature myelinating Schwann cells within $\sim 12$ weeks (Ziegler et al., 2011). Similarly, hESCs can be directed towards an SCP fate and further differentiated into mature Schwann cells over 4 weeks using a combination of chemical small molecule inhibitors including a GSK3 inhibitor (CT99021), TGF$\beta$ inhibitor (SB431452), NRG1, and forskolin (Kim et al., 2017). The generation of SCPs has potential advantages in therapeutic applications. For instance, repair Schwann cells mimic an embryonic Schwann cell phenotype, and hence use of a pure SCP population may fare better in a clinical setting compared to mature myelinating Schwann cells. Second, SCPs are an expandable cell population, and thus better suited in a clinical setting compared to mature Schwann cells.

The design of these directed differentiation approaches is rooted in a solid understanding of developmental events. NRG1 is a critical regulator of Schwann cell differentiation, acting cooperatively with CAMP, the production of which is induced by forskolin (Arthur-Farraj et al., 2011; Bacallao and Monje, 2015). GSK3 inhibitors serve as Wnt agonists, a pathway that induces Sox10 expression, a master regulator of Schwann cell development (Tawk et al., 2011). Finally, TGF- $\beta$ signaling induces Schwann cell apoptosis, so blocking this pathway may aid the survival of derivative glial cells (Parkinson et al., 2001).

(2) Directed differentiation of somatic stem cells: adult skin dermis, which can be obtained from patients with minimal morbidity, has a reservoir of multipotent mesenchymal stem cells similar to embryonic NCCs (Biernaskie, 2010). 


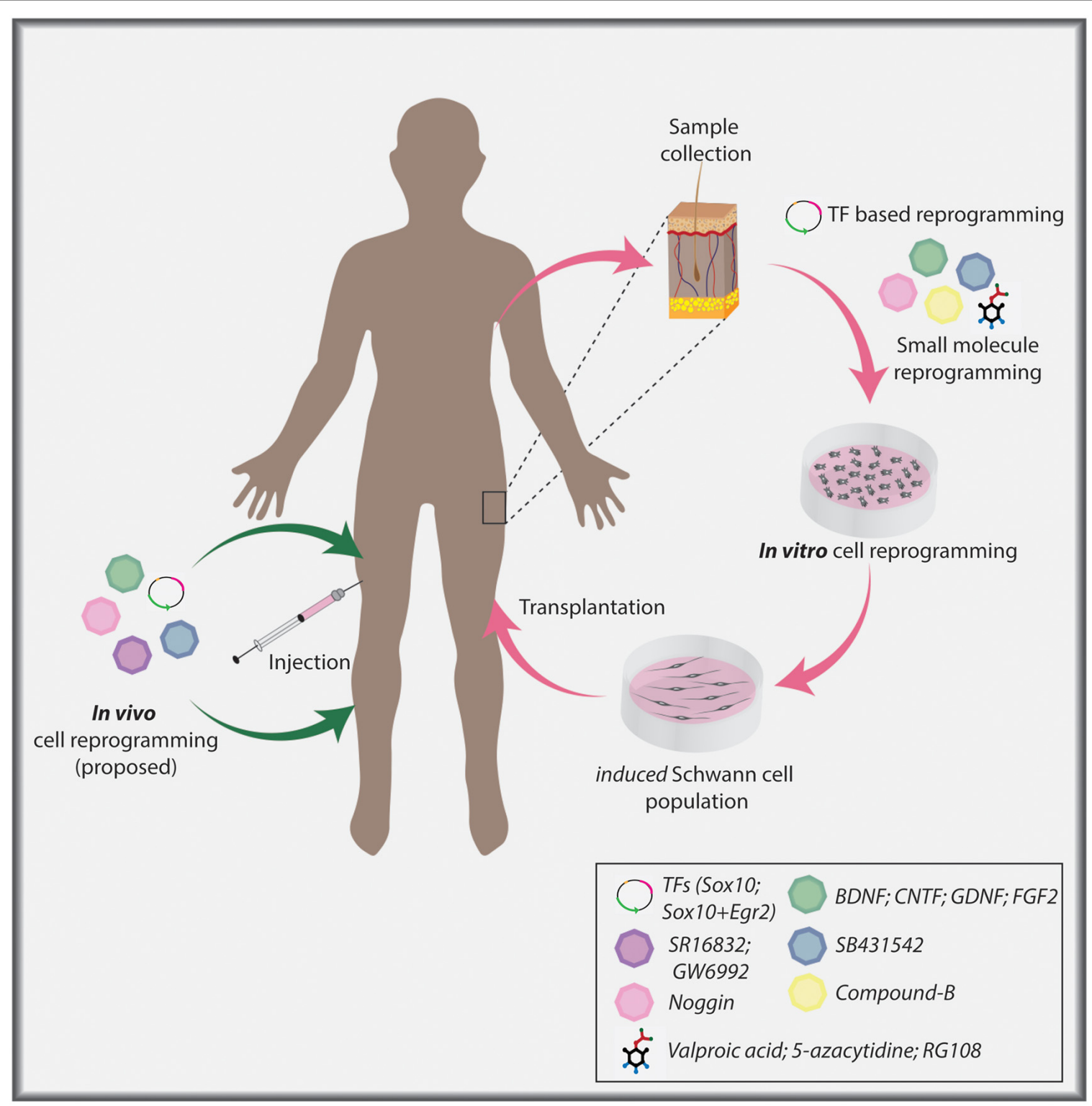

FIGURE 3 | Cellular reprogramming approach to generate induced Schwann cells. Skin biopsy samples isolated from individuals can be used to collect dermal fibroblasts for in vitro culture. Fibroblasts can undergo lineage conversion to a Schwann cell fate under the direction of TF determinants, signaling molecules, and small molecules. Ultimately, induced Schwann cells can be used in a clinical setting to aid nerve repair post-PNI. Current TF-based lineage conversion strategies use Sox10 or Sox10+Egr2. Small molecules employed to generate Schwann cells include Valproic acid (VPA), 5-azacytidine (5-Aza), SB431542, CHIR/CT99021/CP21, RG108. Signaling molecules include Noggin, BDNF, GDNF, and FGF2. In the future, in vivo cellular reprogramming may become a reality using combinatorial approaches.

These NCC-related somatic stem cells, termed skin-derived precursors (SKPs), readily differentiate into NCC progeny, including Schwann cells, in response to appropriate cues (Toma et al., 2001, 2005; Fernandes et al., 2004; McKenzie et al., 2006; Krause et al., 2014). By removal of FGF2 and EGF followed by addition of N2 supplement, forskolin, and NRG1, SKPs from facial skin differentiate into skin-Schwann cells that can be expanded over multiple passages, and when transplanted, skin-Schwann cells associate with axons and generate myelin (Toma et al., 2005; Biernaskie et al.,
2006; McKenzie et al., 2006). Notably, skin-Schwann cells re-initiate the expression of several embryonic Schwann cell genes, including Pou3f1, Tfap2a, Sox2, and Jun (Krause et al., 2014). Moreover, skin-Schwann cells exhibit better proliferative and myelination abilities in comparison to adult nerve-derived Schwann cells (Khuong et al., 2014).

The therapeutic potential of skin-Schwann cells has been studied in both acute and chronic nerve injury settings in rodent models with encouraging results (Walsh et al., 2009, 2010; Khuong et al., 2014; Kumar et al., 2016). However, a 
major limitation remains, which is that skin-Schwann cells take extended periods to expand ( $\sim 6$ weeks) to levels that might be used clinically (McKenzie et al., 2006). Moreover, incomplete conversion of these somatic stem cells to a Schwann cell fate could result in tumorigenesis (May et al., 2018). Nonetheless, these studies opened the possibility that Schwann cells can be successfully acquired through multiple sources other than a nerve biopsy.

There are potential issues associated with directed differentiation strategies using pluripotent and somatic stem cell sources that must be considered. For example, the use of hESCs for directed differentiation is invariably associated with ethical concerns as well as tumorigenic potential (Blum and Benvenisty, 2008; Zakrzewski et al., 2019). Similarly, Schwann cells generated by the differentiation of human adipose-derived mesenchymal stem cells were found to revert to a stem cell-like state upon withdrawal of glial induction factors from the differentiation media (Faroni et al., 2016). Thus, the differentiated Schwann cells must be assessed in the absence of stimulatory cues over extended cell passages, to determine the stability of the cell phenotype.

\section{Introduction to Cellular Reprogramming}

An alternative approach to generate Schwann cells for repair is cellular reprogramming, which converts accessible sources of terminally differentiated somatic cells to a Schwann cell fate (Lujan and Wernig, 2013). The design of such strategies has been built on an extensive body of work investigating the design principles of Schwann cell development and repair, as described in the previous sections. Considerations for cellular reprogramming include the starting cell type and reprogramming factors. A commonly used somatic cell source amenable to lineage conversion are fibroblasts, which are typically obtained from human foreskin (Malik and Rao, 2013; Bajpai et al., 2017) or $3 \mathrm{~mm}$ skin punch biopsies of the dermis (Streckfuss-Bömeke et al., 2013; Castro-Viñuelas et al., 2020). Lineage conversion of fibroblasts is achieved by the overexpression of lineagespecifying TFs and/or by the addition of extrinsic factors such as growth factors or small molecule antagonists or agonists, which specify alternative cell identities, repress the identity of the starting cell type, and remove epigenetic barriers to alter cell state (Lewitzky and Yamanaka, 2007; Qin et al., 2017). Initial reprogramming studies focused on generating iPSCs from fibroblasts by overexpressing the Yamanaka factors (c-Myc-Klf4-Sox2-Oct4, Takahashi and Yamanaka, 2006) and then differentiating iPSCs into the cell type of interest. However, the need to transit through a pluripotent stem cell state poses several problems, including the possibility of generating partially reprogrammed cells that may proliferate and/or differentiate erroneously (Takahashi and Yamanaka, 2016). Moreover, iPSCs are self-renewing stem cells, and are thus potentially tumorigenic. Consequently, more recent studies have looked at direct cellular reprogramming as an alternative approach (Ieda et al., 2010; Sekiya and Suzuki, 2011; Son et al., 2011).
(1) TF mediated reprogramming: examples of direct cellular reprogramming include the trans-differentiation of fibroblasts to a neuronal fate (Son et al., 2011; Victor et al., 2014; Wainger et al., 2015) or oligodendrocyte fate (Najm et al., 2013; Yang N. et al., 2013) without first going to a pluripotent stage, both involving the use of select sets of developmental TFs. Notably, oligodendrocytes, the myelinating glial cells of the CNS have been induced using an eight TF cocktail including the core TFs Sox10-Olig2Nkx6.2 (Najm et al., 2013), or with a triple TF approach (Sox10-Olig2-Zfp536; Yang N. et al., 2013), and finally, by overexpression of Sox10 alone (Weider et al., 2015). In general, TF cocktails include at least one pioneer factor, which aids lineage conversion by binding to and opening sites of closed chromatin. For example, reprogramming of fibroblasts to a neuronal fate includes Ascl1, which acts as a pioneer factor and accesses closed chromatin sites in fibroblasts (Vierbuchen et al., 2010; Zaret and Mango, 2016). Ascl1 then recruits Brn2 and Myt1 to these sites to aid reprogramming, with Myt1 repressing alternative cell fates and Brn2 activating neuronal lineage genes (Wapinski et al., 2013; Zaret and Mango, 2016). Similarly, Olig2 is incorporated in oligodendrocyte reprogramming protocols for its function as a pioneer factor (Yu et al., 2013), as are Sox family genes (Soufi et al., 2015; Hou et al., 2017).

(2) Small molecule mediated reprogramming: cell permeable, chemical small molecules have also been used to promote desired, alternative cell fates in fibroblasts (Wang et al., 2014). For example, reprogramming of human fibroblasts into glutamatergic neurons used a chemical cocktail consisting of a Wnt agonist/GSK3 inhibitor (CHIR99021), TGF- $\beta$ inhibitor (RepSox), HDAC inhibitor (Valproic acid, VPA), and protein kinase A agonist (Forskolin; Hu et al., 2015). Similarly, mouse fibroblasts have been converted into glutamatergic neurons using a similar cocktail involving CHIR99021, Forskolin, ISX9 (promotes neurogenesis), and I-BET151 (bromodomain inhibitor; Li et al., 2015). Thus, small molecule and TF-based approaches can be used independently or in conjunction with efficient cell reprogramming.

\section{Reprogramming of Somatic Cells to a Schwann Cell Fate}

Reprogramming of adult fibroblasts to a Schwann cell fate has been achieved using either TFs or small molecules (Figure 3; Kim et al., 2014; Thoma et al., 2014; Mazzara et al., 2017; Sowa et al., 2017; Kitada et al., 2019). The first success came from the conversion of fibroblasts first to an NCC state by misexpressing Sox10, a critical Schwann cell determinant as outlined above, and culturing cells with VPA and 5-Azacytidine (inhibitor of DNA methylation) to open the chromatin, and CHIR99021 (Wnt agonist/GSK3 inhibitor), to activate Wnt signaling (Kim et al., 2014). HDAC and DNA methylation inhibitors make target cells amenable to reprogramming by opening the chromatin so that TFs that act as lineage-specifiers can bind to target sites and facilitate Schwann cell differentiation to a myelinating phenotype 
(Chen et al., 2011; Jacob et al., 2011; Brugger et al., 2015). Induced NCCs were further differentiated into mature Schwann cells by providing appropriate environmental cues, including NRG1 and cAMP (Kim et al., 2014), which act together to promote a myelinating Schwann cell phenotype, as highlighted above (Arthur-Farraj et al., 2011; Bacallao and Monje, 2015), and FGF2, a Schwann cell mitogen post-PNI (Grothe et al., 2001). More recently, Schwann cells were generated from adult human fibroblasts by overexpressing Sox10 and Egr2, a pro-myelinating factor described above, together with forskolin, NRG1, FGF2, and PDGF, the latter also a Schwann cell mitogen (Mazzara et al., 2017; Sowa et al., 2017).

Investigators have also successfully employed small molecules (VPA and Compound B-undefined) to reprogram fibroblasts to a transient neural precursor state (Thoma et al., 2014). These proliferative intermediate cells were then treated with Noggin [BMP inhibitor, to block neuronal induction by BMPs (Dore et al., 2009)], SB431542 (TGF- $\beta$ inhibitor), and CP21 (GSK3 inhibitor) and differentiated into Schwann cells by culturing in a neural differentiation media enriched with B27 and N2 supplements, BDNF, GDNF, and dibutyrylcAMP. As indicated above, BDNF and GDNF are upregulated in Schwann cells post-injury and have anti-apoptotic effects (Funakoshi et al., 1993; Hoke et al., 2000). A more recent study used a cocktail of chemical small molecules with all-trans retinoic acid, FGF2, forskolin, PDGF-AA, and NRG1 to generate Schwann cells from fibroblasts (Kitada et al., 2019). Thus, there are wide-ranging protocols now available for investigators to adapt to their studies, all of which are based on prior molecular studies of Schwann cell development and the repair phenotype.

Notably, early reprogramming protocols required $\sim 6$ weeks for the first appearance of mature Schwann cell markers (Kim et al., 2014; Thoma et al., 2014), whereas newer studies observed Schwann cell marker expression within 9-21 days of treatment (Mazzara et al., 2017; Sowa et al., 2017; Kitada et al., 2019). However, it is important to consider that several of the protocols produced a heterogeneous population of Schwann cells representing early and late developmental stages (Sowa et al., 2017; Kitada et al., 2019), with additional maturation protocols required to obtain mature myelinating Schwann cells. More recently, induced SCPs were generated from human fibroblasts by misexpressing pluripotency factors (OCT4, SOX2, KLF4, MYCL1, LIN28, p53 shRNA) in fibroblasts using episomal vectors, followed by the use of an induction medium enriched with NRG1 and a host of small molecules [e.g., CT-99021, Wnt agonist/GSK3 inhibitor; RG108, DNA methyltransferase inhibitor; 5'-(N-ethylcarboxamido) adenosine, adenosine receptor- and cAMP agonist; Kim et al., 2020]. Induced SCPs of high purity were generated in nearly 3 weeks with this approach, and only one additional week was required to differentiate the induced SCPs into mature Schwann cells, significantly reducing the reprogramming time-period (Kim et al., 2020). Investigators are thus getting closer to manageable periods for generating induced Schwann cells for clinical purposes.

\section{Future Perspectives}

Directed differentiation and cellular reprogramming strategies have effectively changed the landscape of autologous cell replacement therapy in the past decade and realistically presents an alternative therapeutic approach (Srivastava and DeWitt, 2016). While in vitro cellular reprogramming has dominated reprogramming studies in mammalian systems, there is always the potential that "rogue" cells that have not fully transdifferentiated may become tumorigenic, and if transplants are not autologous, lifelong immunosuppression is required. One development that may have far-reaching implications is the incorporation of a "suicide" gene cassette that is activated when reprogrammed cells proliferate aberrantly (Liang et al., 2018). Besides, the generation of iPSCs that can serve as universal donors by immune cloaking, may also eliminate the need for immunosuppression, although the safety of such an approach remains under debate (Harding et al., 2019; González et al., 2020; Harding et al., 2020). Nevertheless, exogenous cell-based glial support therapies continue to be under development.

Other important considerations for the future design of lineage conversion strategies is the optimal and minimal combination of TFs to be used to convert somatic cells into Schwann cells in the shortest period that are the most efficacious for repair. Apart from Sox10 and Egr2, overexpression of other TFs expressed in repair Schwann cells, as described above (e.g., Sox2, Jun, Pax3, Egr1, Olig1), may prove beneficial in improving reprogramming efficiencies. In the future, Schwann cells generated via direct differentiation or cellular reprogramming could be used in a stand-alone fashion for transplantation or supplemented in nerve conduits to aid nerve remyelination (Biernaskie et al., 2007; Mozafari et al., 2015; Sparling et al., 2015; Assinck et al., 2020). Schwann cells derived from rodent SKPs were demonstrated to successfully repair and remyelinate axons in the injured/diseased CNS as well (Biernaskie et al., 2007; Mozafari et al., 2015; Sparling et al., 2015; Assinck et al., 2020). Thus, Schwann cells generated through alternate sources have found applications beyond the PNS. Generation of Schwann cells via cellular reprogramming also permits in vitro disease modeling for demyelinating disorders and provides a platform for studying the molecular mechanisms underlying such disorders (Mazzara et al., 2017).

An important alternative for future consideration is "in vivo" or "in situ" cellular reprogramming', which targets resident cells for lineage conversion, and in theory, may allow ready integration of trans-differentiated cells into existing micro-environments (Srivastava and DeWitt, 2016). An added advantage of in vivo reprogramming is the potential for quicker treatments, as it will not be necessary to extract cells and grow them ex vivo for protracted periods. Notably, in vivo reprogramming was carried out in rodent models as early as 2008 for the generation of $\beta$ cells from pancreatic exocrine cells using a TF cocktail (Ngn3, Pdx1, Mafa, Zhou et al., 2008). However, several shortcomings (e.g., optimum targeting of the host cell, conversion efficiency, survival post-conversion, as well as conversion into altered cell fates leading to a tumor-like state Ofenbauer and Tursun, 2019) have limited the widespread 
use of such an approach. Nevertheless, advances in in vivo reprogramming are being made (Guo et al., 2014; Nishimura et al., 2014; Liu et al., 2015; Niu et al., 2015), and may soon be applied to the PNS. For instance, in the CNS, the conversion of reactive astrocytes to neurons was achieved using a "clinicallyfriendly" adeno-associated virus (AAV) to express NeuroD1 in an ischemic injury model, leading to improved behavioral outcomes (Chen et al., 2020). A similar approach involving AAV mediated expression of NeuroD1 and Dlx2 was used to generate neurons from striatal astrocytes in a Huntington disease model system (Wu et al., 2020). Finally, in vivo reprogramming of astrocytes into neurons by knocking-down $\mathrm{PTB}$, an RNA-binding protein, was reported in a Parkinson's disease model (Qian et al., 2020).

Notably, direct in vivo reprogramming to treat brain pathologies holds immense potential as target astrocytes are numerous. In contrast, in vivo reprogramming in the PNS may be more complicated as there are fewer cells to directly target for the generation of Schwann cells, and indeed, what is the optimal target cell remains an open question. Fibroblasts are commonly used for in vitro lineage conversion to a Schwann cell identity, however, fibroblasts in the nerve (i.e., in the endoneurium, perineurium, epineurium), even those that migrate to the injury site post-injury (Parrinello et al., 2010; Roberts et al., 2017), may prove difficult to target for in vivo reprogramming due to their location as well as low cell numbers. Notably, endoneurial fibroblasts expand post nerve injury, and differentiate into skeletogenic and dermal tissue, thereby promoting tissue repair (Carr et al., 2019), and may serve as a potential target for direct in vivo reprogramming if techniques for precise targeting are developed. Thus, it remains to be seen whether in vivo reprogramming, for example using an AAV to direct expression of Sox10 and Egr2, could ultimately be employed as a therapeutic approach for PNI repair (Figure 3).

\section{CONCLUSION}

Glial cells are often considered to be "supporting cast" members in the nervous system, with ancillary roles in providing nutrient and structural support to neurons. However, glial cells have many essential roles, including the myelination of nerves to allow information to be transmitted rapidly and

\section{REFERENCES}

Abate, C., and Curran, T. (1990). Encounters with fos and jun on the road to AP-1. Semin. Cancer Biol. 1, 19-26.

Adameyko, I., Lallemend, F., Furlan, A., Zinin, N., Aranda, S., Kitambi, S. S., et al. (2012). Sox 2 and mitf cross-regulatory interactions consolidate progenitor and melanocyte lineages in the cranial neural crest. Development 139, 397-410. doi: 10.1242/dev.065581

Agudo, M., Woodhoo, A., Webber, D., Mirsky, R., Jessen, K. R., and McMahon, S. B. (2008). Schwann cell precursors transplanted into the injured spinal cord multiply, integrate and are permissive for axon growth. Glia 56, 1263-1270. doi: 10.1002/glia.20695

Ahmad, S. T., Rogers, A. D., Chen, M. J., Dixit, R., Adnani, L., Frankiw, L. S., et al. (2019). Capicua regulates neural stem cell proliferation and lineage efficiently. As reviewed herein, we have come a long way towards understanding the molecular and cellular events that underlie Schwann cell development and their functions in repair. This information is proving essential in the design of new repair strategies for PNI, as nerve grafts alone often yield poor results, which can be attributed in part to the limited regenerative potential of endogenous Schwann cells (Kelsey et al., 1997; Saheb-Al-Zamani et al., 2013; Poppler et al., 2016; Hoben et al., 2018; Kornfeld et al., 2019). Alternative approaches to enhance nerve repair have been tested, including grafting nerve-like conduits containing autologous cultured Schwann cells to aid nerve regeneration (Hood et al., 2009). With the emerging successes of Schwann cell transplantation that are now in clinical trials (NCT01739023, NCT03999424, NCT04465929, NCT02480777, NCT02354625, NCT02510079; Saberi et al., 2008, 2011; Zhou et al., 2012; Anderson et al., 2017), optimizing strategies to efficiently acquire and/or generate repair Schwann cells in a shorter time frame is of the essence. Therapeutic approaches for the treatment of PNI involving the generation of Schwann cells using an in situ directed reprogramming protocol or by the exogenous introduction of repair-like Schwann cells generated in a dish may soon be a reality. Taken together, the realization of autologous Schwann cell therapy for effective clinical use is anticipated to be within our grasp.

\section{AUTHOR CONTRIBUTIONS}

$\mathrm{AB}$ and CS: conceptualization. AB, LB, T-HC, RM, JB, and CS: writing-review and editing. TF: artwork. CS, JB, and RM: funding acquisition. All authors contributed to the article and approved the submitted version.

\section{FUNDING}

This research was funded by the Canadian Institutes of Health Research (Project Grant PJT- 156366) to CS, JB, and RM.

\section{ACKNOWLEDGMENTS}

CS holds the Dixon Family Chair in Ophthalmology Research at the Sunnybrook Research Institute.

specification through control of Ets factors. Nat. Commun. 10:2000 doi: 10.1038/s41467-019-09949-6

Akiyama, H., Chaboissier, M.-C., Martin, J. F., Schedl, A., and de Crombrugghe, B. (2002). The transcription factor Sox 9 has essential roles in successive steps of the chondrocyte differentiation pathway and is required for expression of Sox5 and Sox6. Genes Dev. 16, 2813-2828. doi: 10.1101/gad.1017802

Allodi, I., Mecollari, V., González-Péez, F., Eggers, R., Hoyng, S., Verhaagen, J., et al. (2014). Schwann cells transduced with a lentiviral vector encoding Fgf-2 promote motor neuron regeneration following sciatic nerve injury. Glia 62 , 1736-1746. doi: 10.1002/glia.22712

Anderson, K. D., Guest, J. D., Dietrich, W. D., Bartlett Bunge, M., Curiel, R., Dididze, M., et al. (2017). Safety of autologous human Schwann cell transplantation in subacute thoracic spinal cord injury. J. Neurotrauma 34, 2950-2963. doi: 10.1089/neu.2016.4895 
Arroyo, E. J., Bermingham, J. R. Jr., Rosenfeld, M. G., and Scherer, S. S. (1998). Promyelinating Schwann cells express Tst-1/SCIP/Oct-6. J. Neurosci. 18, 7891-7902. doi: 10.1523/JNEUROSCI.18-19-07891.1998

Arthur-Farraj, P. J., Latouche, M., Wilton, D. K., Quintes, S., Chabrol, E., Banerjee, A., et al. (2012). c-Jun reprograms Schwann cells of injured nerves to generate a repair cell essential for regeneration. Neuron 75, 633-647. doi: 10.1016/j.neuron.2012.06.021

Arthur-Farraj, P. J., Morgan, C. C., Adamowicz, M., Gomez-Sanchez, J. A., Fazal, S. V., Beucher, A., et al. (2017). Changes in the coding and non-coding transcriptome and DNA methylome that define the Schwann cell repair phenotype after nerve injury. Cell Rep. 20, 2719-2734. doi: 10.1016/j.celrep. 2017.08.064

Arthur-Farraj, P., Wanek, K., Hantke, J., Davis, C. M., Jayakar, A., Parkinson, D. B., et al. (2011). Mouse Schwann cells need both NRG1 and cyclic AMP to myelinate. Glia 59, 720-733. doi: 10.1002/glia.21144

Assinck, P., Sparling, J. S., Dworski, S., Duncan, G. J., Wu, D. L., Liu, J., et al. (2020). Transplantation of skin precursor-derived Schwann cells yields better locomotor outcomes and reduces bladder pathology in rats with chronic spinal cord injury. Stem Cell Reports 15, 140-155. doi: 10.1016/j.stemcr.2020. 05.017

Bacallao, K., and Monje, P. V. (2015). Requirement of cAMP signaling for Schwann cell differentiation restricts the onset of myelination. PLoS One 10:e0116948. doi: 10.1371/journal.pone.0116948

Baggiolini, A., Varum, S., Mateos, J. M., Bettosini, D., John, N., Bonalli, M., et al. (2015). Premigratory and migratory neural crest cells are multipotent in vivo. Cell Stem Cell 16, 314-322. doi: 10.1016/j.stem.2015.02.017

Bajpai, V. K., Kerosuo, L., Tseropoulos, G., Cummings, K. A., Wang, X., Lei, P., et al. (2017). Reprogramming postnatal human epidermal keratinocytes toward functional neural crest fates. Stem Cells 35, 1402-1415. doi: 10.1002/ stem. 2583

Balakrishnan, A., Belfiore, L., Vasan, L., Touahri, Y., Stykel, M., Fleming, T., et al. (2020). Etv5 is not required for Schwann cell development but is required to regulate the Schwann cell response to peripheral nerve injury. BioRxiv [Preprint]. doi: 10.1101/2020.09.23.309815

Balakrishnan, A., Stykel, M. G., Touahri, Y., Stratton, J. A., Biernaskie, J., and Schuurmans, C. (2016). Temporal analysis of gene expression in the murine Schwann cell lineage and the acutely injured postnatal nerve. PLoS One 11:e0153256. doi: 10.1371/journal.pone.0153256

Beirowski, B., Adalbert, R., Wagner, D., Grumme, D. S., Addicks, K., Ribchester, R. R., et al. (2005). The progressive nature of wallerian degeneration in wild-type and slow wallerian degeneration (WldS) nerves. BMC Neurosci. 6:6. doi: 10.1186/1471-2202-6-6

Benninger, Y., Thurnherr, T., Pereira, J. A., Krause, S., Wu, X., ChrostekGrashoff, A., et al. (2007). Essential and distinct roles for cdc42 and racl in the regulation of Schwann cell biology during peripheral nervous system development. J. Cell Biol. 177, 1051-1061. doi: 10.1083/jcb.2006 10108

Berrocal, Y. A., Almeida, V. W., Gupta, R., and Levi, A. D. (2013a). Transplantation of Schwann cells in a collagen tube for the repair of large, segmental peripheral nerve defects in rats. J. Neurosurg. 119, 720-732. doi: 10.3171/2013.4.JNS121189

Berrocal, Y. A., Almeida, V. W., and Levi, A. D. (2013b). Limitations of nerve repair of segmental defects using acellular conduits. J. Neurosurg. 119, 733-738. doi: 10.3171/2013.4.JNS121938

Betters, E., Liu, Y., Kjaeldgaard, A., Sundström, E., and Garcia-Castro, M. I. (2010). Analysis of early human neural crest development. Dev. Biol. 344, 578-592. doi: 10.1016/j.ydbio.2010.05.012

Bi, W., Huang, W., Whitworth, D. J., Deng, J. M., Zhang, Z., Behringer, R. R., et al. (2001). Haploinsufficiency of sox 9 results in defective cartilage primordia and premature skeletal mineralization. Proc. Natl. Acad. Sci. U S A 98, 6698-6703. doi: 10.1073/pnas.111092198

Biernaskie, J. (2010). Human hair follicles: "bulging" with neural crest-like stem cells. J. Invest. Dermatol. 130, 1202-1204. doi: 10.1038/jid.2009.449

Biernaskie, J. A., McKenzie, I. A., Toma, J. G., and Miller, F. D. (2006). Isolation of skin-derived precursors (SKPs) and differentiation and enrichment of their Schwann cell progeny. Nat. Protoc. 1, 2803-2812. doi: 10.1038/nprot.2006.422

Biernaskie, J., Sparling, J. S., Liu, J., Shannon, C. P., Plemel, J. R., Xie, Y., et al. (2007). Skin-derived precursors generate myelinating Schwann cells that promote remyelination and functional recovery after contusion spinal cord injury. J. Neurosci. 27, 9545-9559. doi: 10.1523/JNEUROSCI.1930-07.2007

Blake, J. A., and Ziman, M. R. (2013). The characterisation of Pax3 expressant cells in adult peripheral nerve. PLoS One 8:e59184. doi: 10.1371/journal.pone. 0059184

Blanchard, A. D., Sinanan, A., Parmantier, E., Zwart, R., Broos, L., Meijer, D., et al. (1996). Oct-6 (SCIP/Tst-1) is expressed in Schwann cell precursors, embryonic Schwann cells and postnatal myelinating Schwann cells: comparison with Oct1, Krox-20 and Pax-3. J. Neurosci. Res. 46, 630-640. doi: 10.1002/(SICI)10974547(19961201)46:5<630::AID-JNR11>3.0.CO;2-0

Blum, B., and Benvenisty, N. (2008). The tumorigenicity of human embryonic stem cells. Adv. Cancer Res. 100, 133-158. doi: 10.1016/S0065-230X(08) 00005-5

Bondurand, N., Girard, M., Pingault, V., Lemort, N., Dubourg, O., and Goossens, M. (2001). Human connexin 32, a gap junction protein altered in the X-linked form of charcot-marie-tooth disease, is directly regulated by the transcription factor SOX10. Hum. Mol. Genet. 10, 2783-2795. doi: $10.1093 / \mathrm{hmg} / 10.24 .2783$

Boyd, J. G., and Gordon, T. (2003). Glial cell line-derived neurotrophic factor and brain-derived neurotrophic factor sustain the axonal regeneration of chronically axotomized motoneurons in vivo. Exp. Neurol. 183, 610-619. doi: 10.1016/s0014-4886(03)00183-3

Boyle, K., Azari, M. F., Cheema, S. S., and Petratos, S. (2005). TNF $\alpha$ mediates Schwann cell death by upregulating p75NTR expression without sustained activation of NFאB. Neurobiol. Dis. 20, 412-427. doi: 10.1016/j.nbd.2005.03.022

Brand, M., and Morrissey, E. (2020). Single-cell fate decisions of bipotential hematopoietic progenitors. Curr. Opin. Hematol. 27, 232-240. doi: 10.1097/MOH.0000000000000592

Bremer, M., Fröb, F., Kichko, T., Reeh, P., Tamm, E. R., Suter, U., et al. (2011). Sox10 is required for Schwann-cell homeostasis and myelin maintenance in the adult peripheral nerve. Glia 59, 1022-1032. doi: 10.1002/glia. 21173

Brosius Lutz, A., Chung, W.-S., Sloan, S. A., Carson, G. A., Zhou, L., Lovelett, E., et al. (2017). Schwann cells use TAM receptor-mediated phagocytosis in addition to autophagy to clear myelin in a mouse model of nerve injury. Proc. Natl. Acad. Sci. U S A 114, E8072-E8080. doi: 10.1073/pnas.17105 66114

Brugger, V., Engler, S., Pereira, J. A., Ruff, S., Horn, M., Welzl, H., et al. (2015). HDAC1/2-dependent P0 expression maintains paranodal and nodal integrity independently of myelin stability through interactions with neurofascins. PLoS Biol. 13:e1002258. doi: 10.1371/journal.pbio.1002258

Buttner, R., Schulz, A., Reuter, M., Akula, A. K., Mindos, T., Carlstedt, A., et al. (2018). Inflammaging impairs peripheral nerve maintenance and regeneration. Aging Cell 17:e12833. doi: 10.1111/acel.12833

Cai, S., Tsui, Y.-P., Tam, K.-W., Shea, G. K.-H., Chang, R. S.-K., Ao, Q., et al. (2017). Directed differentiation of human bone marrow stromal cells to fate-committed Schwann cells. Stem Cell Reports 9, 1097-1108. doi: 10.1016/j. stemcr.2017.08.004

Carr, M. J., Toma, J. S., Johnston, A. P. W., Steadman, P. E., Yuzwa, S. A., Mahmud, N., et al. (2019). Mesenchymal precursor cells in adult nerves contribute to mammalian tissue repair and regeneration. Cell Stem Cell 24, 240.e9-256.e9. doi: 10.1016/j.stem.2018.10.024

Castro-Viñuelas, R., Sanjurjo-Rodríguez, C., Piñeiro-Ramil, M., HermidaGómez, T., Rodríguez-Fernández, S., Oreiro, N., et al. (2020). Generation and characterization of human induced pluripotent stem cells (iPSCs) from hand osteoarthritis patient-derived fibroblasts. Sci. Rep. 10:4272. doi: 10.1038/s41598-020-61071-6

Cattin, A. L., Burden, J. J., Van Emmenis, L., Mackenzie, F. E., Hoving, J. J. A., Garcia Calavia, N., et al. (2015). Macrophage-induced blood vessels guide Schwann cell-mediated regeneration of peripheral nerves. Cell 162, 1127-1139. doi: 10.1016/j.cell.2015.07.021

Cervellini, I., Galino, J., Zhu, N., Allen, S., Birchmeier, C., and Bennett, D. L. (2018). Sustained MAPK/ERK activation in adult Schwann cells impairs nerve repair. J. Neurosci. 38, 679-690. doi: 10.1523/JNEUROSCI. 2255-17.2017

Chaudhry, V., and Cornblath, D. R. (1992). Wallerian degeneration in human nerves: serial electrophysiological studies. Muscle Nerve 15, 687-693. doi: $10.1002 /$ mus. 880150610 
Chen, B., Chen, Q., Parkinson, D. B., and Dun, X.-P. (2019). Analysis of Schwann cell migration and axon regeneration following nerve injury in the sciatic nerve bridge. Front. Mol. Neurosci. 12:308. doi: 10.3389/fnmol.2019.00308

Chen, J., Chu, Y. F., Chen, J. M., and Li, B. C. (2010). Synergistic effects of NGF, $\mathrm{CNTF}$ and GDNF on functional recovery following sciatic nerve injury in rats. Adv. Med. Sci. 55, 32-42. doi: 10.2478/v10039-010-0020-9

Chen, S., Velardez, M. O., Warot, X., Yu, Z.-X., Miller, S. J., Cros, D., et al. (2006). Neuregulin 1-erbB signaling is necessary for normal myelination and sensory function. J. Neurosci. 26, 3079-3086. doi: 10.1523/JNEUROSCI.378505.2006

Chen, W. A., Luo, T. D., Barnwell, J. C., Smith, T. L., and Li, Z. (2017). Agedependent Schwann cell phenotype regulation following peripheral nerve injury. J. Hand Surg. Asian Pac. 22, 464-471. doi: 10.1142/S0218810417500514

Chen, Y.-C., Ma, N.-X., Pei, Z.-F., Wu, Z., Do-Monte, F. H., Keefe, S., et al. (2020). A neuroD1 AAV-based gene therapy for functional brain repair after ischemic injury through in vivo astrocyte-to-neuron conversion. Mol. Ther. 28, 217-234. doi: 10.1016/j.ymthe.2019.09.003

Chen, Y., Wang, H., Yoon, S. O., Xu, X., Hottiger, M. O., Svaren, J., et al.

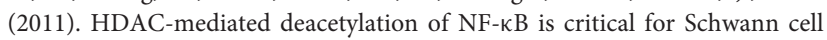
myelination. Nat. Neurosci. 14, 437-441. doi: 10.1038/nn.2780

Cheung, M., and Briscoe, J. (2003). Neural crest development is regulated by the transcription factor Sox9. Development 130, 5681-5693. doi: 10.1242/dev.00808

Cole, J. S., Messing, A., Trojanowski, J. Q., and Lee, V. M. (1994). Modulation of axon diameter and neurofilaments by hypomyelinating Schwann cells in transgenic mice. J. Neurosci. 14, 6956-6966. doi: 10.1523/JNEUROSCI.14-1106956.1994

Cosgaya, J. M., Chan, J. R., and Shooter, E. M. (2002). The neurotrophin receptor p75NTR as a positive modulator of myelination. Science 298, 1245-1248. doi: 10.1126/science.1076595

Coulpier, F., Le Crom, S., Maro, G. S., Manent, J., Giovannini, M., Maciorowski, Z., et al. (2009). Novel features of boundary cap cells revealed by the analysis of newly identified molecular markers. Glia 57, 1450-1457. doi: 10.1002/glia. 20862

Davies, A. M. (1998). Neuronal survival: early dependence on Schwann cells. Curr. Biol. 8, R15-R18. doi: 10.1016/s0960-9822(98)70009-0

Davis, J. B., and Stroobant, P. (1990). Platelet-derived growth factors and fibroblast growth factors are mitogens for rat Schwann cells. J. Cell Biol. 110, 1353-1360. doi: $10.1083 /$ jcb.110.4.1353

Dellon, A. L., and Mackinnon, S. E. (1988). An alternative to the classical nerve graft for the management of the short nerve gap. Plast. Reconstr. Surg. 82, 849-856. doi: 10.1097/00006534-198811000-00020

Deng, Y., Wu, L. M. N., Bai, S., Zhao, C., Wang, H., Wang, J., et al. (2017). A reciprocal regulatory loop between TAZ/YAP and G-protein galphas regulates Schwann cell proliferation and myelination. Nat. Commun. 8:15161. doi: 10.1038/ncomms15161

Doddrell, R. D., Dun, X.-P., Moate, R. M., Jessen, K. R., Mirsky, R., and Parkinson, D. B. (2012). Regulation of Schwann cell differentiation and proliferation by the Pax-3 transcription factor. Glia 60, 1269-1278. doi: 10.1002/glia.22346

Dong, Z., Brennan, A., Liu, N., Yarden, Y., Lefkowitz, G., Mirsky, R., et al. (1995). Neu differentiation factor is a neuron-glia signal and regulates survival, proliferation and maturation of rat Schwann cell precursors. Neuron 15, 585-596. doi: 10.1016/0896-6273(95)90147-7

Dore, J. J., DeWitt, J. C., Setty, N., Donald, M. D., Joo, E., Chesarone, M. A., et al. (2009). Multiple signaling pathways converge to regulate bonemorphogenetic-protein-dependent glial gene expression. Dev. Neurosci. 31, 473-486. doi: 10.1159/000210187

Duman, M., Martinez-Moreno, M., Jacob, C., and Tapinos, N. (2020). Functions of histone modifications and histone modifiers in Schwann cells. Glia 68, 1584-1595. doi: 10.1002/glia.23795

Dyachuk, V., Furlan, A., Shahidi, M. K., Giovenco, M., Kaukua, N., Konstantinidou, C., et al. (2014). Neurodevelopment. Parasympathetic neurons originate from nerve-associated peripheral glial progenitors. Science 345, 82-87. doi: 10.1126/science. 1253281

Espinosa-Medina, I., Outin, E., Picard, C. A., Chettouh, Z., Dymecki, S., Consalez, G. G., et al. (2014). Neurodevelopment. Parasympathetic ganglia derive from Schwann cell precursors. Science 345, 87-90. doi: 10.1126/science. 1253286
Falls, D. L. (2003). Neuregulins: functions, forms and signaling strategies. Exp. Cell Res. 284, 14-30. doi: 10.1016/s0014-4827(02)00102-7

Faroni, A., Smith, R. J., Lu, L., and Reid, A. J. (2016). Human schwann-like cells derived from adipose-derived mesenchymal stem cells rapidly de-differentiate in the absence of stimulating medium. Eur. J. Neurosci. 43, 417-430. doi: 10.1111/ejn.13055

Fazal, S. V., Gomez-Sanchez, J. A., Wagstaff, L. J., Musner, N., Otto, G., Janz, M., et al. (2017). Graded elevation of c-Jun in Schwann cells in vivo: gene dosage determines effects on development, remyelination, tumorigenesis and hypomyelination. J. Neurosci. 37, 12297-12313. doi: 10.1523/JNEUROSCI. 0986-17.2017

Feltri, M. L., Poitelon, Y., and Previtali, S. C. (2015). How Schwann cells sort axons: new concepts. Neuroscientist 22, 252-265. doi: 10.1177/1073858415572361

Fernandes, K. J., McKenzie, I. A., Mill, P., Smith, K. M., Akhavan, M., BarnabéHeider, F., et al. (2004). A dermal niche for multipotent adult skin-derived precursor cells. Nat. Cell Biol. 6, 1082-1093. doi: 10.1038/ncb1181

Ferri, C. C., and Bisby, M. A. (1999). Improved survival of injured sciatic nerve Schwann cells in mice lacking the p75 receptor. Neurosci. Lett. 272, 191-194. doi: 10.1016/s0304-3940(99)00618-7

Finzsch, M., Schreiner, S., Kichko, T., Reeh, P., Tamm, E. R., Bösl, M. R., et al. (2010). Sox10 is required for Schwann cell identity and progression beyond the immature Schwann cell stage. J. Cell Biol. 189, 701-712. doi: 10.1083/jcb. 200912142

Fleming, M. S., Li, J. J., Ramos, D., Li, T., Talmage, D. A., Abe, S.-I., et al. (2016). A RET-ER81-NRG1 signaling pathway drives the development of pacinian corpuscles. J. Neurosci. 36, 10337-10355. doi: 10.1523/JNEUROSCI.2160-16. 2016

Fontana, X., Hristova, M., Da Costa, C., Patodia, S., Thei, L., Makwana, M., et al. (2012). c-Jun in Schwann cells promotes axonal regeneration and motoneuron survival via paracrine signaling. J. Cell Biol. 198, 127-141. doi: 10.1083/jcb. 201205025

Fregnan, F., Muratori, L., Simões, A. R., Giacobini-Robecchi, M. G., and Raimondo, S. (2012). Role of inflammatory cytokines in peripheral nerve injury. Neural Regen. Res. 7, 2259-2266. doi: 10.3969/j.issn.1673-5374.2012.29. 003

Fujiwara, S., Hoshikawa, S., Ueno, T., Hirata, M., Saito, T., Ikeda, T., et al. (2014). SOX10 transactivates S100B to suppress Schwann cell proliferation and to promote myelination. PLoS One 9:e115400. doi: 10.1371/journal.pone. 0115400

Funakoshi, H., Frisén, J., Barbany, G., Timmusk, T., Zachrisson, O., Verge, V. M., et al. (1993). Differential expression of mRNAs for neurotrophins and their receptors after axotomy of the sciatic nerve. J. Cell Biol. 123, 455-465. doi: $10.1083 /$ jcb.123.2.455

Garratt, A. N., Britsch, S., and Birchmeier, C. (2000). Neuregulin, a factor with many functions in the life of a Schwann cell. BioEssays 22, 987-996. doi: 10.1002/1521-1878(200011)22:11<987::AID-BIES5>3.0.CO;2-5

Gaudet, A. D., Popovich, P. G., and Ramer, M. S. (2011). Wallerian degeneration: gaining perspective on inflammatory events after peripheral nerve injury. J. Neuroinflammation 8:110. doi: 10.1186/1742-2094-8-110

Gerber, D., Ghidinelli, M., Tinelli, E., Somandin, C., Gerber, J., Pereira, J. A., et al. (2019). Schwann cells, but not oligodendrocytes, depend strictly on dynamin 2 function. eLife 8:e42404. doi: 10.7554/eLife.42404

Gersey, Z. C., Burks, S. S., Anderson, K. D., Dididze, M., Khan, A., Dietrich, W. D., et al. (2017). First human experience with autologous Schwann cells to supplement sciatic nerve repair: report of 2 cases with long-term follow-up. Neurosurg. Focus 42:E2. doi: 10.3171/2016.12.FOCUS16474

Ghazvini, M., Mandemakers, W., Jaegle, M., Piirsoo, M., Driegen, S., Koutsourakis, M., et al. (2002). A cell type-specific allele of the POU gene oct-6 reveals Schwann cell autonomous function in nerve development and regeneration. EMBO J. 21, 4612-4620. doi: 10.1093/emboj/ cdf475

Ghislain, J., and Charnay, P. (2006). Control of myelination in Schwann cells: a Krox 20 cis-regulatory element integrates oct6, brn 2 and sox 10 activities. EMBO Rep. 7, 52-58. doi: 10.1038/sj.embor.7400573

Giannaccini, M., Calatayud, M. P., Poggetti, A., Corbianco, S., Novelli, M., Paoli, M., et al. (2017). Magnetic nanoparticles for efficient delivery of growth factors: stimulation of peripheral nerve regeneration. Adv. Healthc. Mater. 6:1601429. doi: 10.1002/adhm.201601429 
Gilliatt, R. W., and Hjorth, R. J. (1972). Nerve conduction during Wallerian degeneration in the baboon. J. Neurol. Neurosurg. Psychiatry 35, 335-341. doi: 10.1136/jnnp.35.3.335

Gomez-Sanchez, J. A., Carty, L., Iruarrizaga-Lejarreta, M., Palomo-Irigoyen, M., Varela-Rey, M., Griffith, M., et al. (2015). Schwann cell autophagy, myelinophagy, initiates myelin clearance from injured nerves. J. Cell Biol. 210, 153-168. doi: $10.1083 /$ jcb.201503019

Gomez-Sanchez, J. A., Lopez de Armentia, M., Lujan, R., Kessaris, N., Richardson, W. D., and Cabedo, H. (2009). Sustained axon-glial signaling induces Schwann cell hyperproliferation, remak bundle myelination and tumorigenesis. J. Neurosci. 29, 11304-11315. doi: 10.1523/JNEUROSCI.175309.2009

Gomez-Sanchez, J. A., Pilch, K. S., van der Lans, M., Fazal, S. V., Benito, C., Wagstaff, L. J., et al. (2017). After nerve injury, lineage tracing shows that myelin and remak Schwann cells elongate extensively and branch to form repair Schwann cells, which shorten radically on remyelination. J. Neurosci. 37, 9086-9099. doi: 10.1523/JNEUROSCI.1453-17.2017

Gonçalves, N. P., Mohseni, S., El Soury, M., Ulrichsen, M., Richner, M., Xiao, J., et al. (2019). Peripheral nerve regeneration is independent from Schwann cell p75(NTR) expression. Front. Cell. Neurosci. 13:235. doi: 10.3389/fncel.2019. 00235

González, B. J., Creusot, R. J., Sykes, M., and Egli, D. (2020). How safe are universal pluripotent stem cells? Cell Stem Cell 27:346. doi: 10.1016/j.stem.2020.07.001

Goulding, M. D., Chalepakis, G., Deutsch, U., Erselius, J. R., and Gruss, P. (1991). Pax-3, a novel murine DNA binding protein expressed during early neurogenesis. EMBO J. 10, 1135-1147.

Griffin, J. W., and Thompson, W. J. (2008). Biology and pathology of nonmyelinating Schwann cells. Glia 56, 1518-1531. doi: 10.1002/glia.20778

Grothe, C., Meisinger, C., and Claus, P. (2001). In vivo expression and localization of the fibroblast growth factor system in the intact and lesioned rat peripheral nerve and spinal ganglia. J. Comp. Neurol. 434, 342-357. doi: 10.1002/cne.1181

Grove, M., Kim, H., Santerre, M., Krupka, A. J., Han, S. B., Zhai, J., et al. (2017). YAP/TAZ initiate and maintain Schwann cell myelination. eLife 6:e20982. doi: 10.7554/eLife.20982

Grove, M., Lee, H., Zhao, H., and Son, Y.-J. (2020). Axon-dependent expression of YAP/TAZ mediates Schwann cell remyelination but not proliferation after nerve injury. eLife 9:e50138. doi: 10.7554/eLife.50138

Guo, L., Moon, C., Zheng, Y., and Ratner, N. (2013). Cdc42 regulates Schwann cell radial sorting and myelin sheath folding through NF2/merlin-dependent and independent signaling. Glia 61, 1906-1921. doi: 10.1002/glia.22567

Guo, Z., Zhang, L., Wu, Z., Chen, Y., Wang, F., and Chen, G. (2014). In vivo direct reprogramming of reactive glial cells into functional neurons after brain injury and in an Alzheimer's disease model. Cell Stem Cell 14, 188-202. doi: 10.1016/j. stem.2013.12.001

Hagedorn, L., Paratore, C., Brugnoli, G., Baert, J. L., Mercader, N., Suter, U., et al. (2000). The Ets domain transcription factor erm distinguishes rat satellite glia from Schwann cells and is regulated in satellite cells by neuregulin signaling. Dev. Biol. 219, 44-58. doi: 10.1006/dbio.1999.9595

Haines, J. D., Fragoso, G., Hossain, S., Mushynski, W. E., and Almazan, G. (2008). P38 mitogen-activated protein kinase regulates myelination. J. Mol. Neurosci. 35, 23-33. doi: 10.1007/s12031-007-9011-0

Hall, S. M., Li, H., and Kent, A. P. (1997). Schwann cells responding to primary demyelination in vivo express p75NTR and c-erbB receptors: a light and electron immunohistochemical study. J. Neurocytol. 26, 679-690. doi: 10.1023/a:1018502012347

Harding, J., Vintersten-Nagy, K., and Nagy, A. (2020). Universal stem cells: making the unsafe safe. Cell Stem Cell 27, 198-199. doi: 10.1016/j.stem.2020. 07.004

Harding, J., Vintersten-Nagy, K., Shutova, M., Yang, H., Tang, J. K., Massumi, M., et al. (2019). Induction of long-term allogeneic cell acceptance and formation of immune privileged tissue in immunocompetent hosts. BioRxiv [Preprint]. doi: 10.1101/716571

Hardy, M., Reddy, U. R., and Pleasure, D. (1992). Platelet-derived growth factor and regulation of Schwann cell proliferation in vivo. J. Neurosci. Res. 31, 254-262. doi: 10.1002/jnr.490310206

Harrisingh, M. C., Perez-Nadales, E., Parkinson, D. B., Malcolm, D. S., Mudge, A. W., and Lloyd, A. C. (2004). The Ras/Raf/ERK signalling pathway drives Schwann cell dedifferentiation. EMBO J. 23, 3061-3071. doi: 10.1038/sj. emboj.7600309

Harty, B. L., Coelho, F., Pease-Raissi, S. E., Mogha, A., Ackerman, S. D., Herbert, A. L., et al. (2019). Myelinating Schwann cells ensheath multiple axons in the absence of E3 ligase component Fbxw7. Nat. Commun. 10:2976. doi: 10.1038/s41467-019-10881-y

Harty, B. L., and Monk, K. R. (2017). Unwrapping the unappreciated: recent progress in remak Schwann cell biology. Curr. Opin. Neurobiol. 47, 131-137. doi: 10.1016/j.conb.2017.10.003

Hausott, B., and Klimaschewski, L. (2019). Promotion of peripheral nerve regeneration by stimulation of the extracellular signal-regulated kinase (ERK) pathway. Anat. Rec. 302, 1261-1267. doi: 10.1002/ar.24126

He, Y., Kim, J. Y., Dupree, J., Tewari, A., Melendez-Vasquez, C., Svaren, J., et al. (2010). Yy1 as a molecular link between neuregulin and transcriptional modulation of peripheral myelination. Nat. Neurosci. 13, 1472-1480. doi: $10.1038 / \mathrm{nn} .2686$

Hilton, D. A., Jacob, J., Househam, L., and Tengah, C. (2007). Complications following sural and peroneal nerve biopsies. J. Neurol. Neurosurg. Psychiatry 78, 1271-1272. doi: 10.1136/jnnp.2007.116368

Hirata, K., and Kawabuchi, M. (2002). Myelin phagocytosis by macrophages and nonmacrophages during wallerian degeneration. Microsc. Res. Tech. 57, 541-547. doi: 10.1002/jemt.10108

Hoben, G. M., Ee, X., Schellhardt, L., Yan, Y., Hunter, D. A., Moore, A. M., et al. (2018). Increasing nerve autograft length increases senescence and reduces regeneration. Plast. Reconstr. Surg. 142, 952-961. doi: 10.1097/PRS. 0000000000004759

Hoke, A., Cheng, C., and Zochodne, D. W. (2000). Expression of glial cell line-derived neurotrophic factor family of growth factors in peripheral nerve injury in rats. Neuroreport 11, 1651-1654. doi: 10.1097/00001756-20000605000011

Höke, A., Ho, T., Crawford, T. O., LeBel, C., Hilt, D., and Griffin, J. W. (2003). Glial cell line-derived neurotrophic factor alters axon Schwann cell units and promotes myelination in unmyelinated nerve fibers. J. Neurosci. 23, 561-567. doi: 10.1523/JNEUROSCI.23-02-00561.2003

Honoré, S. M., Aybar, M. J., and Mayor, R. (2003). Sox10 is required for the early development of the prospective neural crest in xenopus embryos. Dev. Biol. 260, 79-96. doi: 10.1016/s0012-1606(03)00247-1

Hood, B., Levene, H. B., and Levi, A. D. (2009). Transplantation of autologous Schwann cells for the repair of segmental peripheral nerve defects. Neurosurg. Focus 26:E4. doi: 10.3171/FOC.2009.26.2.E4

Hou, L., Srivastava, Y., and Jauch, R. (2017). Molecular basis for the genome engagement by sox proteins. Semin. Cell Dev. Biol. 63, 2-12. doi: 10.1016/j. semcdb.2016.08.005

Hu, W., Qiu, B., Guan, W., Wang, Q., Wang, M., Li, W., et al. (2015). Direct conversion of normal and Alzheimer's disease human fibroblasts into neuronal cells by small molecules. Cell Stem Cell 17, 204-212. doi: 10.1016/j.stem.2015. 07.006

Huang, C.-W., Lu, S.-Y., Huang, T.-C., Huang, B.-M., Sun, H. S., Yang, S.-H., et al. (2020). FGF9 induces functional differentiation to Schwann cells from human adipose derived stem cells. Theranostics 10, 2817-2831. doi: 10.7150/thno. 38553

Huebner, E. A., and Strittmatter, S. M. (2009). Axon regeneration in the peripheral and central nervous systems. Results Probl. Cell Differ. 48, 339-351. doi: 10.1007/400_2009_19

Ichihara, S., Inada, Y., and Nakamura, T. (2008). Artificial nerve tubes and their application for repair of peripheral nerve injury: an update of current concepts. Injury 39, 29-39. doi: 10.1016/j.injury.2008.08.029

Ieda, M., Fu, J.-D., Delgado-Olguin, P., Vedantham, V., Hayashi, Y., Bruneau, B. G., et al. (2010). Direct reprogramming of fibroblasts into functional cardiomyocytes by defined factors. Cell 142, 375-386. doi: 10.1016/j. cell.2010.07.002

Ishii, A., Furusho, M., and Bansal, R. (2013). Sustained activation of ERK1/2 MAPK in oligodendrocytes and Schwann cells enhances myelin growth and stimulates oligodendrocyte progenitor expansion. J. Neurosci. 33, 175-186. doi: 10.1523/JNEUROSCI.4403-12.2013

Jacob, C., Christen, C. N., Pereira, J. A., Somandin, C., Baggiolini, A., Lotscher, P., et al. (2011). HDAC1 and HDAC2 control the transcriptional program of 
myelination and the survival of Schwann cells. Nat. Neurosci. 14, 429-436. doi: $10.1038 / \mathrm{nn} .2762$

Jang, S.-W., and Svaren, J. (2009). Induction of myelin protein zero by early growth response 2 through upstream and intragenic elements. J. Biol. Chem. 284, 20111-20120. doi: 10.1074/jbc.M109.022426

Jang, S. Y., Shin, Y. K., Park, S. Y., Park, J. Y., Lee, H. J., Yoo, Y. H., et al. (2016). Autophagic myelin destruction by Schwann cells during wallerian degeneration and segmental demyelination. Glia 64, 730-742. doi: 10.1002/glia.22957

Jessen, K. R. (2004). Glial cells. Int. J. Biochem. Cell Biol. 36, 1861-1867. doi: 10.1016/j.biocel.2004.02.023

Jessen, K. R., and Mirsky, R. (2005). The origin and development of glial cells in peripheral nerves. Nat. Rev. Neurosci. 6, 671-682. doi: 10.1038/nrn1746

Jessen, K. R., and Mirsky, R. (2016). The repair Schwann cell and its function in regenerating nerves. J. Physiol. 594, 3521-3531. doi: 10.1113/JP270874

Jessen, K. R., and Mirsky, R. (2019a). Schwann cell precursors: multipotent glial cells in embryonic nerves. Front. Mol. Neurosci. 12:69. doi: 10.3389/fnmol.2019. 00069

Jessen, K. R., and Mirsky, R. (2019b). The success and failure of the Schwann cell response to nerve injury. Front. Cell. Neurosci. 13:33. doi: 10.3389/fncel.2019. 00033

Johnston, A. P., Yuzwa, S. A., Carr, M. J., Mahmud, N., Storer, M. A., Krause, M. P., et al. (2016). Dedifferentiated Schwann cell precursors secreting paracrine factors are required for regeneration of the mammalian digit tip. Cell Stem Cell 19, 433-448. doi: 10.1016/j.stem.2016.06.002

Jones, E. A., Brewer, M. H., Srinivasan, R., Krueger, C., Sun, G., Charney, K. N., et al. (2012). Distal enhancers upstream of the charcot-marie-tooth type 1A disease gene PMP22. Hum. Mol. Genet. 21, 1581-1591. doi: $10.1093 / \mathrm{hmg} / \mathrm{ddr} 595$

Jones, E. A., Jang, S.-W., Mager, G. M., Chang, L.-W., Srinivasan, R., Gokey, N. G., et al. (2007). Interactions of sox 10 and egr2 in myelin gene regulation. Neuron Glia Biol. 3, 377-387. doi: 10.1017/S1740925X08000173

Kao, S.-C., Wu, H., Xie, J., Chang, C.-P., Ranish, J. A., Graef, I. A., et al. (2009). Calcineurin/NFAT signaling is required for neuregulin-regulated Schwann cell differentiation. Science 323, 651-654. doi: 10.1126/science.1166562

Kelsey, J. L., Praemer, A., Nelson, L., Felberg, A., and Rice, L. M. (1997). Upper Extremity Disorders: Frequency, Impact and Cost. New York: Churchill Livingstone Inc.

Kemp, S. W., Syed, S., Walsh, W., Zochodne, D. W., and Midha, R. (2009). Collagen nerve conduits promote enhanced axonal regeneration, Schwann cell association and neovascularization compared to silicone conduits. Tissue Eng. Part A 15, 1975-1988. doi: 10.1089/ten.tea.2008.0338

Kemp, S. W. P., Walsh, S. K., and Midha, R. (2008). Growth factor and stem cell enhanced conduits in peripheral nerve regeneration and repair. Neurol. Res. 30, 1030-1038. doi: 10.1179/174313208X362505

Kennedy, A. D., and DeLeo, F. R. (2009). Neutrophil apoptosis and the resolution of infection. Immunol. Res. 43, 25-61. doi: 10.1007/s12026-008-8049-6

Khuong, H. T., Kumar, R., Senjaya, F., Grochmal, J., Ivanovic, A., Shakhbazau, A., et al. (2014). Skin derived precursor Schwann cells improve behavioral recovery for acute and delayed nerve repair. Exp. Neurol. 254, 168-179. doi: 10.1016/j. expneurol.2014.01.002

Khursigara, G., Bertin, J., Yano, H., Moffett, H., DiStefano, P. S., and Chao, M. V. (2001). A prosurvival function for the p75 receptor death domain mediated via the caspase recruitment domain receptor-interacting protein 2. J. Neurosci. 21, 5854-5863. doi: 10.1523/JNEUROSCI.21-16-05854.2001

Kim, H.-S., Kim, J. Y., Song, C. L., Jeong, J. E., and Cho, Y. S. (2020). Directly induced human Schwann cell precursors as a valuable source of Schwann cells. Stem Cell Res. Ther. 11:257. doi: 10.1186/s13287-020-01772-x

Kim, H.-S., Lee, J., Lee, D. Y., Kim, Y.-D., Kim, J. Y., Lim, H. J., et al. (2017). Schwann cell precursors from human pluripotent stem cells as a potential therapeutic target for myelin repair. Stem Cell Reports 8, 1714-1726. doi: 10.1016/j.stemcr.2017.04.011

Kim, J., Lo, L., Dormand, E., and Anderson, D. J. (2003). SOX10 maintains multipotency and inhibits neuronal differentiation of neural crest stem cells. Neuron 38, 17-31. doi: 10.1016/s0896-6273(03)00163-6

Kim, Y. J., Lim, H., Li, Z., Oh, Y., Kovlyagina, I., Choi, I. Y., et al. (2014). Generation of multipotent induced neural crest by direct reprogramming of human postnatal fibroblasts with a single transcription factor. Cell Stem Cell 15, 497-506. doi: 10.1016/j.stem.2014.07.013
Kioussi, C., Gross, M. K., and Gruss, P. (1995). Pax3: a paired domain gene as a regulator in PNS myelination. Neuron 15, 553-562. doi: 10.1016/08966273(95)90144-2

Kitada, M., Murakami, T., Wakao, S., Li, G., and Dezawa, M. (2019). Direct conversion of adult human skin fibroblasts into functional Schwann cells that achieve robust recovery of the severed peripheral nerve in rats. Glia 67, 950-966. doi: 10.1002/glia.23582

Klaes, A., Menne, T., Stollewerk, A., Scholz, H., and Klämbt, C. (1994). The Ets transcription factors encoded by the Drosophila gene pointed direct glial cell differentiation in the embryonic CNS. Cell 78, 149-160. doi: 10.1016/00928674(94)90581-9

Ko, K. R., Lee, J., Lee, D., Nho, B., and Kim, S. (2018). Hepatocyte growth factor (HGF) promotes peripheral nerve regeneration by activating repair Schwann cells. Sci. Rep. 8:8316. doi: 10.1038/s41598-018-26704-x

Kokubu, N., Tsujii, M., Akeda, K., Iino, T., and Sudo, A. (2018). BMP-7/Smad expression in dedifferentiated Schwann cells during axonal regeneration and upregulation of endogenous BMP-7 following administration of PTH(1-34). J. Orthop. Surg. 26:2309499018812953. doi: 10.1177/2309499018812953

Kornfeld, T., Vogt, P. M., Bucan, V., Peck, C.-T., Reimers, K., and Radtke, C. (2016). Characterization and Schwann cell seeding of up to $15.0 \mathrm{~cm}$ long spider silk nerve conduits for reconstruction of peripheral nerve defects. J. Funct. Biomater. 7:30. doi: 10.3390/jfb7040030

Kornfeld, T., Vogt, P. M., and Radtke, C. (2019). Nerve grafting for peripheral nerve injuries with extended defect sizes. Wien Med. Wochenschr. 169, 240-251. doi: 10.1007/s10354-018-0675-6

Kovacic, U., Zele, T., Osredkar, J., Sketelj, J., and Bajrović, F. F. (2004). Sex-related differences in the regeneration of sensory axons and recovery of nociception after peripheral nerve crush in the rat. Exp. Neurol. 189, 94-104. doi: 10.1016/j. expneurol.2004.05.015

Krause, M. P., Dworski, S., Feinberg, K., Jones, K., Johnston, A. P., Paul, S., et al. (2014). Direct genesis of functional rodent and human Schwann cells from skin mesenchymal precursors. Stem Cell Reports 3, 85-100. doi: 10.1016/j.stemcr. 2014.05.011

Kuhlbrodt, K., Herbarth, B., Sock, E., Hermans-Borgmeyer, I., and Wegner, M. (1998). Sox10, a novel transcriptional modulator in glial cells. J. Neurosci. 18, 237-250. doi: 10.1523/JNEUROSCI.18-01-00237.1998

Kumar, R., Sinha, S., Hagner, A., Stykel, M., Raharjo, E., Singh, K. K., et al. (2016). Adult skin-derived precursor Schwann cells exhibit superior myelination and regeneration supportive properties compared to chronically denervated nervederived Schwann cells. Exp. Neurol. 278, 127-142. doi: 10.1016/j.expneurol. 2016.02.006

Lavasani, M., Thompson, S. D., Pollett, J. B., Usas, A., Lu, A., Stolz, D. B., et al. (2014). Human muscle-derived stem/progenitor cells promote functional murine peripheral nerve regeneration. J. Clin. Invest. 124, 1745-1756. doi: 10.1172/JCI44071

Le Douarin, N. M., Creuzet, S., Couly, G., and Dupin, E. (2004). Neural crest cell plasticity and its limits. Development 131, 4637-4650. doi: 10.1242/dev.01350

Le Douarin, N. M., and Dupin, E. (2003). Multipotentiality of the neural crest. Curr. Opin. Genet. Dev. 13, 529-536. doi: 10.1016/j.gde.2003.08.002

Le Douarin, K. M. and Kalcheim, C. (1999). The Neural Crest. New York, NY: Cambridge University Press.

LeBlanc, S. E., Jang, S.-W., Ward, R. M., Wrabetz, L., and Svaren, J. (2006). Direct regulation of myelin protein zero expression by the Egr2 transactivator. J. Biol. Chem. 281, 5453-5460. doi: 10.1074/jbc.M512159200

LeBlanc, S. E., Ward, R. M., and Svaren, J. (2007). Neuropathy-associated Egr2 mutants disrupt cooperative activation of myelin protein zero by Egr2 and sox10. Mol. Cell. Biol. 27, 3521-3529. doi: 10.1128/MCB.01689-06

Levi, A. D., Guénard, V., Aebischer, P., and Bunge, R. P. (1994). The functional characteristics of Schwann cells cultured from human peripheral nerve after transplantation into a gap within the rat sciatic nerve. J. Neurosci. 14, 1309-1319. doi: 10.1523/JNEUROSCI.14-03-01309.1994

Lewitzky, M., and Yamanaka, S. (2007). Reprogramming somatic cells towards pluripotency by defined factors. Curr. Opin. Biotechnol. 18, 467-473. doi: 10.1016/j.copbio.2007.09.007

Li, S., Mattar, P., Dixit, R., Lawn, S. O., Wilkinson, G., Kinch, C., et al. (2014). RAS/ERK signaling controls proneural genetic programs in cortical development and gliomagenesis. J. Neurosci. 34, 2169-2190. doi: 10.1523/JNEUROSCI.4077-13.2014 
Li, X., Newbern, J. M., Wu, Y., Morgan-Smith, M., Zhong, J., Charron, J., et al. (2012). MEK is a key regulator of gliogenesis in the developing brain. Neuron 75, 1035-1050. doi: 10.1016/j.neuron.2012.08.031

Li, X., Zuo, X., Jing, J., Ma, Y., Wang, J., Liu, D., et al. (2015). Small-moleculedriven direct reprogramming of mouse fibroblasts into functional neurons. Cell Stem Cell 17, 195-203. doi: 10.1016/j.stem.2015.06.003

Liang, Q., Monetti, C., Shutova, M. V., Neely, E. J., Hacibekiroglu, S., Yang, H., et al. (2018). Linking a cell-division gene and a suicide gene to define and improve cell therapy safety. Nature 563, 701-704. doi: 10.1038/s41586-0180733-7

Liu, J.-H., Tang, Q., Liu, X.-X., Qi, J., Zeng, R.-X., Zhu, Z.-W., et al. (2018). Analysis of transcriptome sequencing of sciatic nerves in Sprague-Dawley rats of different ages. Neural Regen. Res. 13, 2182-2190. doi: 10.4103/16735374.241469

Liu, Q., Spusta, S. C., Mi, R., Lassiter, R. N., Stark, M. R., Hoke, A., et al. (2012). Human neural crest stem cells derived from human ESCs and induced pluripotent stem cells: induction, maintenance and differentiation into functional Schwann cells. Stem Cells Transl. Med. 1, 266-278. doi: 10.5966/sctm.2011-0042

Liu, X., Zhao, Y., Peng, S., Zhang, S., Wang, M., Chen, Y., et al. (2016). BMP7 retards peripheral myelination by activating p38 MAPK in Schwann cells. Sci. Rep. 6:31049. doi: 10.1038/srep31049

Liu, Y., Miao, Q., Yuan, J., Han, S., Zhang, P., Li, S., et al. (2015). Ascll converts dorsal midbrain astrocytes into functional neurons in vivo. J. Neurosci. 35, 9336-9355. doi: 10.1523/JNEUROSCI.3975-14.2015

Lopez-Anido, C., Poitelon, Y., Gopinath, C., Moran, J. J., Ma, K. H., Law, W. D., et al. (2016). Tead1 regulates the expression of peripheral myelin protein 22 during Schwann cell development. Hum. Mol. Genet. 25, 3055-3069. doi: 10.1093/hmg/ddw158

Lu, Q. R., Yuk, D., Alberta, J. A., Zhu, Z., Pawlitzky, I., Chan, J., et al. (2000). Sonic hedgehog-regulated oligodendrocyte lineage genes encoding bHLH proteins in the mammalian central nervous system. Neuron 25, 317-329. doi: 10.1016/s0896-6273(00)80897-1

Lubińska, L. (1982). Patterns of wallerian degeneration of myelinated fibres in short and long peripheral stumps and in isolated segments of rat phrenic nerve. Interpretation of the role of axoplasmic flow of the trophic factor. Brain Res. 233, 227-240. doi: 10.1016/0006-8993(82)91199-4

Lujan, E., and Wernig, M. (2013). An indirect approach to generating specific human cell types. Nat. Methods 10, 44-45. doi: 10.1038/nmeth.2325

Lv, W., Deng, B., Duan, W., Li, Y., Song, X., Ji, Y., et al. (2019). FGF9 alters the wallerian degeneration process by inhibiting Schwann cell transformation and accelerating macrophage infiltration. Brain Res. Bull. 152, 285-296. doi: 10.1016/j.brainresbull.2019.06.011

Ma, K. H., and Svaren, J. (2018). Epigenetic control of Schwann cells. Neuroscientist 24, 627-638. doi: 10.1177/1073858417751112

Magnaghi, V., Veiga, S., Ballabio, M., Gonzalez, L. C., Garcia-Segura, L. M., and Melcangi, R. C. (2006). Sex-dimorphic effects of progesterone and its reduced metabolites on gene expression of myelin proteins by rat Schwann cells. J. Peripher. Nerv. Syst. 11, 111-118. doi: 10.1111/j.1085-9489.2006. 00075.x

Malik, N., and Rao, M. S. (2013). A review of the methods for human iPSC derivation. Methods Mol. Biol. 997, 23-33. doi: 10.1007/978-1-62703-3480_10_3

Maro, G. S., Vermeren, M., Voiculescu, O., Melton, L., Cohen, J., Charnay, P., et al. (2004). Neural crest boundary cap cells constitute a source of neuronal and glial cells of the PNS. Nat. Neurosci. 7, 930-938. doi: 10.1038/nn1299

Martens, W., Sanen, K., Georgiou, M., Struys, T., Bronckaers, A., Ameloot, M., et al. (2014). Human dental pulp stem cells can differentiate into Schwann cells and promote and guide neurite outgrowth in an aligned tissue-engineered collagen construct in vitro. FASEB J. 28, 1634-1643. doi: 10.1096/fj.13-243980

Matsuse, D., Kitada, M., Kohama, M., Nishikawa, K., Makinoshima, H., Wakao, S., et al. (2010). Human umbilical cord-derived mesenchymal stromal cells differentiate into functional Schwann cells that sustain peripheral nerve regeneration. J. Neuropathol. Exp. Neurol. 69, 973-985. doi: 10.1097/NEN. 0b013e3181eff6dc

May, Z., Kumar, R., Fuehrmann, T., Tam, R., Vulic, K., Forero, J., et al. (2018). Adult skin-derived precursor Schwann cell grafts form growths in the injured spinal cord of fischer rats. Biomed. Mater. 13:034101. doi: 10.1088/1748$605 \mathrm{X} / \mathrm{aa} 95 \mathrm{f} 8$

Mazzara, P. G., Massimino, L., Pellegatta, M., Ronchi, G., Ricca, A., Iannielli, A., et al. (2017). Two factor-based reprogramming of rodent and human fibroblasts into Schwann cells. Nat. Commun. 8:14088. doi: $10.1038 /$ ncomms 14088

McKenzie, I. A., Biernaskie, J., Toma, J. G., Midha, R., and Miller, F. D. (2006). Skin-derived precursors generate myelinating Schwann cells for the injured and dysmyelinated nervous system. J. Neurosci. 26, 6651-6660. doi: 10.1523/JNEUROSCI.1007-06.2006

Menorca, R. M., Fussell, T. S., and Elfar, J. C. (2013). Nerve physiology: mechanisms of injury and recovery. Hand Clin. 29, 317-330. doi: 10.1016/j. hcl.2013.04.002

Meyer Zu Reckendorf, S., Brand, C., Pedro, M. T., Hegler, J., Schilling, C. S., Lerner, R., et al. (2020). Lipid metabolism adaptations are reduced in human compared to murine Schwann cells following injury. Nat. Commun. 11:2123. doi: 10.1038/s41467-020-15915-4

Michailov, G. V., Sereda, M. W., Brinkmann, B. G., Fischer, T. M., Haug, B., Birchmeier, C., et al. (2004). Axonal neuregulin-1 regulates myelin sheath thickness. Science 304, 700-703. doi: 10.1126/science.1095862

Miledi, R., and Slater, C. R. (1970). On the degeneration of rat neuromuscular junctions after nerve section. J. Physiol. 207, 507-528. doi: 10.1113/jphysiol. 1970.sp009076

Mindos, T., Dun, X.-P., North, K., Doddrell, R. D. S., Schulz, A., Edwards, P., et al. (2017). Merlin controls the repair capacity of Schwann cells after injury by regulating hippo/YAP activity. J. Cell Biol. 216, 495-510. doi: 10.1083/jcb. 201606052

Mirsky, R., Woodhoo, A., Parkinson, D. B., Arthur-Farraj, P., Bhaskaran, A., and Jessen, K. R. (2008). Novel signals controlling embryonic Schwann cell development, myelination and dedifferentiation. J. Peripher. Nerv. Syst. 13, 122-135. doi: 10.1111/j.1529-8027.2008.00168.x

Monje, P. V., Sant, D., and Wang, G. (2018). Phenotypic and functional characteristics of human Schwann cells as revealed by cell-based assays and RNA-SEQ. Mol. Neurobiol. 55, 6637-6660. doi: 10.1007/s12035-017-0837-3

Monje, P. V., Soto, J., Bacallao, K., and Wood, P. M. (2010). Schwann cell dedifferentiation is independent of mitogenic signaling and uncoupled to proliferation: role of cAMP and JNK in the maintenance of the differentiated state. J. Biol. Chem. 285, 31024-31036. doi: 10.1074/jbc.M110.116970

Monuki, E. S., Kuhn, R., and Lemke, G. (1993). Repression of the myelin P0 gene by the POU transcription factor SCIP. Mech. Dev. 42, 15-32. doi: 10.1016/09254773(93)90095-f

Morrissey, T. K., Kleitman, N., and Bunge, R. P. (1991). Isolation and functional characterization of Schwann cells derived from adult peripheral nerve. J. Neurosci. 11, 2433-2442. doi: 10.1523/JNEUROSCI.11-08-02433.1991

Mozafari, S., Laterza, C., Roussel, D., Bachelin, C., Marteyn, A., Deboux, C., et al. (2015). Skin-derived neural precursors competitively generate functional myelin in adult demyelinated mice. J. Clin. Invest. 125, 3642-3656. doi: 10.1172/JCI80437

Murakami, T., and Sunada, Y. (2019). Schwann cell and the pathogenesis of charcot-marie-tooth disease. Adv. Exp. Med. Biol. 1190, 301-321. doi: 10.1007/978-981-32-9636-7_19

Nagarajan, R., Le, N., Mahoney, H., Araki, T., and Milbrandt, J. (2002). Deciphering peripheral nerve myelination by using Schwann cell expression profiling. Proc. Natl. Acad. Sci. U S A 99, 8998-9003. doi: 10.1073/pnas. 132080999

Najm, F. J., Lager, A. M., Zaremba, A., Wyatt, K., Caprariello, A. V., Factor, D. C., et al. (2013). Transcription factor-mediated reprogramming of fibroblasts to expandable, myelinogenic oligodendrocyte progenitor cells. Nat. Biotechnol. 31, 426-433. doi: 10.1038/nbt.2561

Nakazaki, H., Shen, Y.-W., Yun, B., Reddy, A., Khanna, V., Mania-Farnell, B., et al. (2009). Transcriptional regulation by Pax3 and TGF $\beta 2$ signaling: a potential gene regulatory network in neural crest development. Int. J. Dev. Biol. 53, 69-79. doi: 10.1387/ijdb.082682hn

Napoli, I., Noon, L. A., Ribeiro, S., Kerai, A. P., Parrinello, S., Rosenberg, L. H., et al. (2012). A central role for the ERK-signaling pathway in controlling Schwann cell plasticity and peripheral nerve regeneration in vivo. Neuron 73, 729-742. doi: 10.1016/j.neuron.2011.11.031 
Nave, K.-A. (2010). Myelination and the trophic support of long axons. Nat. Rev. Neurosci. 11, 275-283. doi: 10.1038/nrn2797

Newbern, J. M., Li, X., Shoemaker, S. E., Zhou, J., Zhong, J., Wu, Y., et al. (2011). Specific functions for ERK/MAPK signaling during PNS development. Neuron 69, 91-105. doi: 10.1016/j.neuron.2010.12.003

Niederlander, C., and Lumsden, A. (1996). Late emigrating neural crest cells migrate specifically to the exit points of cranial branchiomotor nerves. Development $122,2367-2374$.

Nikolaeva, M. A., Mukherjee, B., and Stys, P. K. (2005). $\mathrm{Na}^{+-}$dependent sources of intra-axonal $\mathrm{Ca}^{2+}$ release in rat optic nerve during in vitro chemical ischemia. J. Neurosci. 25, 9960-9967. doi: 10.1523/JNEUROSCI.2003-05.2005

Nishimura, K., Weichert, R. M., Liu, W., Davis, R. L., and Dabdoub, A. (2014). Generation of induced neurons by direct reprogramming in the mammalian cochlea. Neuroscience 275, 125-135. doi: 10.1016/j.neuroscience.2014.05.067

Niu, W., Zang, T., Smith, D. K., Vue, T. Y., Zou, Y., Bachoo, R., et al. (2015). SOX2 reprograms resident astrocytes into neural progenitors in the adult brain. Stem Cell Reports 4, 780-794. doi: 10.1016/j.stemcr.2015.03.006

Nocera, G., and Jacob, C. (2020). Mechanisms of Schwann cell plasticity involved in peripheral nerve repair after injury. Cell. Mol. Life Sci. 77, 3977-3989. doi: 10.1007/s00018-020-03516-9

Notterpek, L., Snipes, G. J., and Shooter, E. M. (1999). Temporal expression pattern of peripheral myelin protein 22 during in vivo and in vitro myelination. Glia 25, 358-369.

Ofenbauer, A., and Tursun, B. (2019). Strategies for in vivo reprogramming. Curr. Opin. Cell Biol. 61, 9-15. doi: 10.1016/j.ceb.2019.06.002

Ogata, T., Iijima, S., Hoshikawa, S., Miura, T., Yamamoto, S., Oda, H., et al. (2004). Opposing extracellular signal-regulated kinase and akt pathways control Schwann cell myelination. J. Neurosci. 24, 6724-6732. doi: 10.1523/JNEUROSCI.5520-03.2004

Okawa, S., Angarica, V. E., Lemischka, I., Moore, K., and del Sol, A. (2015). A differential network analysis approach for lineage specifier prediction in stem cell subpopulations. NPJ Syst. Biol. Appl. 1:15012. doi: 10.1038/npjsba.2015.12

Ommer, A., Figlia, G., Pereira, J. A., Datwyler, A. L., Gerber, J., DeGeer, J., et al. (2019). Ral GTPases in Schwann cells promote radial axonal sorting in the peripheral nervous system. J. Cell Biol. 218, 2350-2369. doi: 10.1083/jcb. 201811150

Painter, M. W., Brosius Lutz, A., Cheng, Y.-C., Latremoliere, A., Duong, K., Miller, C. M., et al. (2014). Diminished Schwann cell repair responses underlie age-associated impaired axonal regeneration. Neuron 83, 331-343. doi: 10.1016/j.neuron.2014.06.016

Paratore, C., Brugnoli, G., Lee, H.-Y., Suter, U., and Sommer, L. (2002). The role of the Ets domain transcription factor Erm in modulating differentiation of neural crest stem cells. Dev. Biol. 250, 168-180. doi: 10.1006/dbio.2002.0795

Paratore, C., Goerich, D. E., Suter, U., Wegner, M., and Sommer, L. (2001). Survival and glial fate acquisition of neural crest cells are regulated by an interplay between the transcription factor Sox 10 and extrinsic combinatorial signaling. Development 128, 3949-3961.

Parkinson, D. B., Bhaskaran, A., Arthur-Farraj, P., Noon, L. A., Woodhoo, A., Lloyd, A. C., et al. (2008). c-Jun is a negative regulator of myelination. J. Cell Biol. 181, 625-637. doi: 10.1083/jcb.200803013

Parkinson, D. B., Bhaskaran, A., Droggiti, A., Dickinson, S., D’Antonio, M., Mirsky, R., et al. (2004). Krox-20 inhibits Jun-NH2-terminal kinase/c-Jun to control Schwann cell proliferation and death. J. Cell Biol. 164, 385-394. doi: $10.1083 /$ jcb.200307132

Parkinson, D. B., Dong, Z., Bunting, H., Whitfield, J., Meier, C., Marie, H., et al. (2001). Transforming growth factor beta (TGF $\beta$ ) mediates Schwann cell death in vitro and in vivo: examination of c-Jun activation, interactions with survival signals and the relationship of TGF $\beta$-mediated death to Schwann cell differentiation. J. Neurosci. 21, 8572-8585. doi: 10.1523/JNEUROSCI.21-2108572.2001

Parrinello, S., Napoli, I., Ribeiro, S., Digby, P. W., Fedorova, M., Parkinson, D. B., et al. (2010). EphB signaling directs peripheral nerve regeneration through Sox2-dependent Schwann cell sorting. Cell 143, 145-155. doi: 10.1016/j.cell. 2010.08.039

Peirano, R. I., Goerich, D. E., Riethmacher, D., and Wegner, M. (2000). Protein zero gene expression is regulated by the glial transcription factor Sox10. Mol. Cell. Biol. 20, 3198-3209. doi: 10.1128/mcb.20.9.3198-3209.2000
Perkins, N. M., and Tracey, D. J. (2000). Hyperalgesia due to nerve injury: role of neutrophils. Neuroscience 101, 745-757. doi: 10.1016/s0306-4522(00) 00396-1

Poitelon, Y., Lopez-Anido, C., Catignas, K., Berti, C., Palmisano, M., Williamson, C., et al. (2016). YAP and TAZ control peripheral myelination and the expression of laminin receptors in Schwann cells. Nat. Neurosci. 19, 879-887. doi: 10.1038/nn.4316

Poliak, S., and Peles, E. (2003). The local differentiation of myelinated axons at nodes of ranvier. Nat. Rev. Neurosci. 4, 968-980. doi: 10.1038/nrn1253

Poppler, L. H., Ee, X., Schellhardt, L., Hoben, G. M., Pan, D., Hunter, D. A., et al. (2016). Axonal growth arrests after an increased accumulation of Schwann cells expressing senescence markers and stromal cells in acellular nerve allografts. Tissue Eng. Part A 22, 949-961. doi: 10.1089/ten.TEA.2016.0003

Qian, H., Kang, X., Hu, J., Zhang, D., Liang, Z., Meng, F., et al. (2020). Reversing a model of Parkinson's disease with in situ converted nigral neurons. Nature 582, 550-556. doi: 10.1038/s41586-020-2388-4

Qin, H., Zhao, A., and Fu, X. (2017). Small molecules for reprogramming and transdifferentiation. Cell. Mol. Life Sci. 74, 3553-3575. doi: 10.1007/s00018017-2586-x

Rasband, M. N., and Peles, E. (2015). The nodes of ranvier: molecular assembly and maintenance. Cold Spring Harb. Perspect. Biol. 8:a020495. doi: 10.1101/cshperspect.a020495

Roberts, S. L., Dun, X.-P., Doddrell, R. D. S., Mindos, T., Drake, L. K., Onaitis, M. W., et al. (2017). Sox2 expression in Schwann cells inhibits myelination in vivo and induces influx of macrophages to the nerve. Development 144, 3114-3125. doi: 10.1242/dev.150656

Rodríguez, F. J., Verdú, E., Ceballos, D., and Navarro, X. (2000). Nerve guides seeded with autologous Schwann cells improve nerve regeneration. Exp. Neurol. 161, 571-584. doi: 10.1006/exnr.1999.7315

Ryu, E. J., Wang, J. Y., Le, N., Baloh, R. H., Gustin, J. A., Schmidt, R. E., et al. (2007). Misexpression of Pou3f1 results in peripheral nerve hypomyelination and axonal loss. J. Neurosci. 27, 11552-11559. doi: 10.1523/JNEUROSCI.549706.2007

Saberi, H., Firouzi, M., Habibi, Z., Moshayedi, P., Aghayan, H. R., Arjmand, B., et al. (2011). Safety of intramedullary Schwann cell transplantation for postrehabilitation spinal cord injuries: 2-year follow-up of 33 cases. J. Neurosurg. Spine 15, 515-525. doi: 10.3171/2011.6.SPINE10917

Saberi, H., Moshayedi, P., Aghayan, H.-R., Arjmand, B., Hosseini, S.-K., EmamiRazavi, S. H., et al. (2008). Treatment of chronic thoracic spinal cord injury patients with autologous Schwann cell transplantation: an interim report on safety considerations and possible outcomes. Neurosci. Lett. 443, 46-50. doi: 10.1016/j.neulet.2008.07.041

Saheb-Al-Zamani, M., Yan, Y., Farber, S. J., Hunter, D. A., Newton, P., Wood, M. D., et al. (2013). Limited regeneration in long acellular nerve allografts is associated with increased Schwann cell senescence. Exp. Neurol. 247, 165-177. doi: 10.1016/j.expneurol.2013.04.011

Sakaue, M., and Sieber-Blum, M. (2015). Human epidermal neural crest stem cells as a source of Schwann cells. Development 142, 3188-3197. doi: 10.1242/dev. 123034

Salzer, J. L., and Zalc, B. (2016). Myelination. Curr. Biol. 26, R971-R975. doi: 10.1016/j.cub.2016.07.074

Sarbu, N., Shih, R. Y., Jones, R. V., Horkayne-Szakaly, I., Oleaga, L., and Smirniotopoulos, J. G. (2016). White matter diseases with radiologicpathologic correlation. Radiographics 36, 1426-1447. doi: 10.1148/rg. 2016160031

Sauka-Spengler, T., and Bronner-Fraser, M. (2008). A gene regulatory network orchestrates neural crest formation. Nat. Rev. Mol. Cell Biol. 9, 557-568. doi: $10.1038 / \mathrm{nrm} 2428$

Scheib, J. L., and Hoke, A. (2016). An attenuated immune response by Schwann cells and macrophages inhibits nerve regeneration in aged rats. Neurobiol. Aging 45, 1-9. doi: 10.1016/j.neurobiolaging.2016.05.004

Schlosshauer, B., Dreesmann, L., Schaller, H.-E., and Sinis, N. (2006). Synthetic nerve guide implants in humans: a comprehensive survey. Neurosurgery 59 , 740-747. doi: 10.1227/01.NEU.0000235197.36789.42

Schmid, D., Zeis, T., and Schaeren-Wiemers, N. (2014). Transcriptional regulation induced by cAMP elevation in mouse Schwann cells. ASN Neuro 6, 137-157. doi: 10.1042/AN20130031 
Sedy, J., Tseng, S., Walro, J. M., Grim, M., and Kucera, J. (2006). ETS transcription factor ER81 is required for the pacinian corpuscle development. Dev. Dyn. 235, 1081-1089. doi: 10.1002/dvdy.20710

Sekiya, S., and Suzuki, A. (2011). Direct conversion of mouse fibroblasts to hepatocyte-like cells by defined factors. Nature 475, 390-393. doi: 10.1038/nature10263

Shakhbazau, A., Mohanty, C., Kumar, R., and Midha, R. (2014). Sensory recovery after cell therapy in peripheral nerve repair: effects of naive and skin precursorderived Schwann cells. J. Neurosurg. 121, 423-431. doi: 10.3171/2014.5. JNS132132

Sheean, M. E., McShane, E., Cheret, C., Walcher, J., Muller, T., WulfGoldenberg, A., et al. (2014). Activation of MAPK overrides the termination of myelin growth and replaces $\mathrm{Nrg1/ErbB3}$ signals during Schwann cell development and myelination. Genes Dev. 28, 290-303. doi: 10.1101/gad. 230045.113

Sheu, J. Y., Kulhanek, D. J., and Eckenstein, F. P. (2000). Differential patterns of ERK and STAT3 phosphorylation after sciatic nerve transection in the rat. Exp. Neurol. 166, 392-402. doi: 10.1006/exnr.2000.7508

Snaidero, N., and Simons, M. (2014). Myelination at a glance. J. Cell Sci. 127, 2999-3004. doi: 10.1242/jcs.151043

Son, E. Y., Ichida, J. K., Wainger, B. J., Toma, J. S., Rafuse, V. F., Woolf, C. J., et al. (2011). Conversion of mouse and human fibroblasts into functional spinal motor neurons. Cell Stem Cell 9, 205-218. doi: 10.1016/j.stem.2011. 07.014

Song, X.-Y., Zhou, F.-H.-H., Zhong, J.-H., Wu, L. L., and Zhou, X.-F. (2006). Knockout of p75(NTR) impairs re-myelination of injured sciatic nerve in mice. J. Neurochem. 96, 833-842. doi: 10.1111/j.1471-4159.2005. 03564.x

Sophie, B., Jacob, H., Jordan, V. J. S., Yungki, P., Laura, F. M., and Yannick, P. (2019). YAP and TAZ regulate Cc2d1b and purbeta in Schwann cells. Front. Mol. Neurosci. 12:177. doi: 10.3389/fnmol.2019.00177

Soufi, A., Garcia, M. F., Jaroszewicz, A., Osman, N., Pellegrini, M., and Zaret, K. S, (2015). Pioneer transcription factors target partial DNA motifs on nucleosomes to initiate reprogramming. Cell 161, 555-568. doi: 10.1016/j.cell.2015.03.017

Sowa, Y., Kishida, T., Tomita, K., Yamamoto, K., Numajiri, T., and Mazda, O. (2017). Direct conversion of human fibroblasts into Schwann cells that facilitate regeneration of injured peripheral nerve in vivo. Stem Cells Transl. Med. 6, 1207-1216. doi: 10.1002/sctm.16-0122

Sparling, J. S., Bretzner, F., Biernaskie, J., Assinck, P., Jiang, Y., Arisato, H., et al. (2015). Schwann cells generated from neonatal skin-derived precursors or neonatal peripheral nerve improve functional recovery after acute transplantation into the partially injured cervical spinal cord of the rat. J. Neurosci. 35, 6714-6730. doi: 10.1523/JNEUROSCI.1070-14.2015

Srinivasan, R., Jang, S.-W., Ward, R. M., Sachdev, S., Ezashi, T., and Svaren, J. (2007). Differential regulation of NAB corepressor genes in Schwann cells. BMC Mol. Biol. 8:117. doi: 10.1186/1471-2199-8-117

Srivastava, D., and DeWitt, N. (2016). In vivo cellular reprogramming: the next generation. Cell 166, 1386-1396. doi: 10.1016/j.cell.2016.08.055

Stassart, R. M., and Woodhoo, A. (2020). Axo-glial interaction in the injured PNS. Dev. Neurobiol. doi: 10.1002/dneu.22771

Stenberg, L., and Dahlin, L. B. (2014). Gender differences in nerve regeneration after sciatic nerve injury and repair in healthy and in type 2 diabetic goto-kakizaki rats. BMC Neurosci. 15:107. doi: 10.1186/1471-220215-107

Stewart, H. J., Brennan, A., Rahman, M., Zoidl, G., Mitchell, P. J., Jessen, K. R., et al. (2001). Developmental regulation and overexpression of the transcription factor AP-2, a potential regulator of the timing of Schwann cell generation. Eur. J. Neurosci. 14, 363-372. doi: 10.1046/j.0953-816x.2001.01650.x

Stratton, J. A., Holmes, A., Rosin, N. L., Sinha, S., Vohra, M., Burma, N. E., et al. (2018). Macrophages regulate Schwann cell maturation after nerve injury. Cell Rep. 24, 2561.e6-2572.e6. doi: 10.1016/j.celrep.2018.08.004

Streckfuss-Bömeke, K., Wolf, F., Azizian, A., Stauske, M., Tiburcy, M., Wagner, S., et al. (2013). Comparative study of human-induced pluripotent stem cells derived from bone marrow cells, hair keratinocytes and skin fibroblasts. Eur. Heart J. 34, 2618-2629. doi: 10.1093/eurheartj/ehs203

Stuhlmiller, T. J., and García-Castro, M. I. (2012). Current perspectives of the signaling pathways directing neural crest induction. Cell. Mol. Life Sci. 69, 3715-3737. doi: 10.1007/s00018-012-0991-8
Sunderland, S. (1947). Rate of regeneration in human peripheral nerves: analysis of the interval between injury and onset of recovery. Arch. Neurol. Psychiatry 58, 251-295. doi: 10.1001/archneurpsyc.1947.02300320002001

Syed, N., Reddy, K., Yang, D. P., Taveggia, C., Salzer, J. L., Maurel, P., et al. (2010). Soluble neuregulin-1 has bifunctional, concentrationdependent effects on Schwann cell myelination. J. Neurosci. 30, 6122-6131. doi: 10.1523/JNEUROSCI.1681-09.2010

Takahashi, K., and Yamanaka, S. (2006). Induction of pluripotent stem cells from mouse embryonic and adult fibroblast cultures by defined factors. Cell 126, 663-676. doi: 10.1016/j.cell.2006.07.024

Takahashi, K., and Yamanaka, S. (2016). A decade of transcription factormediated reprogramming to pluripotency. Nat. Rev. Mol. Cell Biol. 17, 183-193. doi: $10.1038 / \mathrm{nrm} .2016 .8$

Tan, D., Wen, J., Li, L., Wang, X., Qian, C., Pan, M., et al. (2018). Inhibition of RhoA-subfamily GTPases suppresses Schwann cell proliferation through regulating AKT pathway rather than ROCK pathway. Front. Cell. Neurosci. 12:437. doi: $10.3389 /$ fncel.2018.00437

Taveggia, C., Zanazzi, G., Petrylak, A., Yano, H., Rosenbluth, J., Einheber, S., et al. (2005). Neuregulin-1 type III determines the ensheathment fate of axons. Neuron 47, 681-694. doi: 10.1016/j.neuron.2005.08.017

Tawk, M., Makoukji, J., Belle, M., Fonte, C., Trousson, A., Hawkins, T., et al. (2011). Wnt/beta-catenin signaling is an essential and direct driver of myelin gene expression and myelinogenesis. J. Neurosci. 31, 3729-3742. doi: 10.1523/JNEUROSCI.4270-10.2011

Thoma, E. C., Merkl, C., Heckel, T., Haab, R., Knoflach, F., Nowaczyk, C., et al. (2014). Chemical conversion of human fibroblasts into functional Schwann cells. Stem Cell Reports 3, 539-547. doi: 10.1016/j.stemcr.2014. 07.014

Toma, J. G., Akhavan, M., Fernandes, K. J., Barnabé-Heider, F., Sadikot, A., Kaplan, D. R., et al. (2001). Isolation of multipotent adult stem cells from the dermis of mammalian skin. Nat. Cell Biol. 3, 778-784. doi: 10.1038/ncb09 01-778

Toma, J. G., McKenzie, I. A., Bagli, D., and Miller, F. D. (2005). Isolation and characterization of multipotent skin-derived precursors from human skin. Stem Cells 23, 727-737. doi: 10.1634/stemcells.2004-0134

Toma, J. S., Karamboulas, K., Carr, M. J., Kolaj, A., Yuzwa, S. A., Mahmud, N., et al. (2020). Peripheral nerve single-cell analysis identifies mesenchymal ligands that promote axonal growth. eNeuro 7:ENEURO.0066-20.2020. doi: 10.1523/ENEURO.0066-20.2020

Tong, L.-L., Ding, Y.-Q., Jing, H.-B., Li, X.-Y., and Qi, J.-G. (2015). Differential motor and sensory functional recovery in male but not female adult rats is associated with remyelination rather than axon regeneration after sciatic nerve crush. Neuroreport 26, 429-437. doi: 10.1097/WNR.00000000000 00366

Topilko, P., Levi, G., Merlo, G., Mantero, S., Desmarquet, C., Mancardi, G., et al. (1997). Differential regulation of the zinc finger genes Krox-20 and Krox-24 (Egr-1) suggests antagonistic roles in Schwann cells. J. Neurosci. Res. 50, 702-712. doi: 10.1002/(SICI)1097-4547(19971201)50:5<702::AID-JNR7>3 $0 . \mathrm{CO} ; 2-\mathrm{L}$

Touma, E., Kato, S., Fukui, K., and Koike, T. (2007). Calpain-mediated cleavage of collapsin response mediator protein(CRMP)-2 during neurite degeneration in mice. Eur. J. Neurosci. 26, 3368-3381. doi: 10.1111/j.1460-9568.2007. 05943.x

Vega-Lopez, G. A., Cerrizuela, S., and Aybar, M. J. (2017). Trunk neural crest cells: formation, migration and beyond. Int. J. Dev. Biol. 61, 5-15. doi: 10.1387/ijdb. $160408 \mathrm{gv}$

Vermeren, M., Maro, G. S., Bron, R., McGonnell, I. M., Charnay, P., Topilko, P., et al. (2003). Integrity of developing spinal motor columns is regulated by neural crest derivatives at motor exit points. Neuron 37, 403-415. doi: 10.1016/s0896-6273(02)01188-1

Verovskaya, E., Broekhuis, M. J., Zwart, E., Ritsema, M., van Os, R., de Haan, G., et al. (2013). Heterogeneity of young and aged murine hematopoietic stem cells revealed by quantitative clonal analysis using cellular barcoding. Blood 122, 523-532. doi: 10.1182/blood-2013-01-481135

Victor, M. B., Richner, M., Hermanstyne, T. O., Ransdell, J. L., Sobieski, C., Deng, P. Y., et al. (2014). Generation of human striatal neurons by microRNAdependent direct conversion of fibroblasts. Neuron 84, 311-323. doi: 10.1016/j. neuron.2014.10.016 
Vierbuchen, T., Ostermeier, A., Pang, Z. P., Kokubu, Y., Südhof, T. C., and Wernig, M. (2010). Direct conversion of fibroblasts to functional neurons by defined factors. Nature 463, 1035-1041. doi: 10.1038/nature08797

Wainger, B. J., Buttermore, E. D., Oliveira, J. T., Mellin, C., Lee, S., Saber, W. A., et al. (2015). Modeling pain in vitro using nociceptor neurons reprogrammed from fibroblasts. Nat. Neurosci. 18, 17-24. doi: 10.1038/nn.3886

Wakamatsu, Y., Endo, Y., Osumi, N., and Weston, J. A. (2004). Multiple roles of Sox2, an HMG-box transcription factor in avian neural crest development. Dev. Dyn. 229, 74-86. doi: 10.1002/dvdy.10498

Wakao, S., Hayashi, T., Kitada, M., Kohama, M., Matsue, D., Teramoto, N., et al. (2010). Long-term observation of auto-cell transplantation in non-human primate reveals safety and efficiency of bone marrow stromal cell-derived Schwann cells in peripheral nerve regeneration. Exp. Neurol. 223, 537-547. doi: 10.1016/j.expneurol.2010.01.022

Walsh, S. K., Gordon, T., Addas, B. M., Kemp, S. W., and Midha, R. (2010). Skin-derived precursor cells enhance peripheral nerve regeneration following chronic denervation. Exp. Neurol. 223, 221-228. doi: 10.1016/j.expneurol.2009. 05.025

Walsh, S., Biernaskie, J., Kemp, S. W., and Midha, R. (2009). Supplementation of acellular nerve grafts with skin derived precursor cells promotes peripheral nerve regeneration. Neuroscience 164, 1097-1107. doi: 10.1016/j.neuroscience. 2009.08.072

Wang, H., Cao, N., Spencer, C. I., Nie, B., Ma, T., Xu, T., et al. (2014). Small molecules enable cardiac reprogramming of mouse fibroblasts with a single factor, Oct4. Cell Rep. 6, 951-960. doi: 10.1016/j.celrep.2014.01.038

Wang, M. S., Davis, A. A., Culver, D. G., Wang, Q., Powers, J. C., and Glass, J. D. (2004). Calpain inhibition protects against taxol-induced sensory neuropathy. Brain 127, 671-679. doi: 10.1093/brain/awh078

Wang, Y., Kim, E., Wang, X., Novitch, B. G., Yoshikawa, K., Chang, L. S., et al. (2012). ERK inhibition rescues defects in fate specification of Nf1-deficient neural progenitors and brain abnormalities. Cell 150, 816-830. doi: 10.1016/j. cell.2012.06.034

Wapinski, O. L., Vierbuchen, T., Qu, K., Lee, Q. Y., Chanda, S., Fuentes, D. R., et al. (2013). Hierarchical mechanisms for direct reprogramming of fibroblasts to neurons. Cell 155, 621-635. doi: 10.1016/j.cell.2013.09.028

Weider, M., Wegener, A., Schmitt, C., Kuspert, M., Hillgartner, S., Bosl, M. R., et al. (2015). Elevated in vivo levels of a single transcription factor directly convert satellite glia into oligodendrocyte-like cells. PLoS Genet. 11:e1005008. doi: 10.1371/journal.pgen.1005008

Weiss, T., Taschner-Mandl, S., Bileck, A., Slany, A., Kromp, F., Rifatbegovic, F., et al. (2016). Proteomics and transcriptomics of peripheral nerve tissue and cells unravel new aspects of the human Schwann cell repair phenotype. Glia 64, 2133-2153. doi: 10.1002/glia.23045

Wilcox, M. B., Laranjeira, S. G., Eriksson, T. M., Jessen, K. R., Mirsky, R., Quick, T. J., et al. (2020). Characterising cellular and molecular features of human peripheral nerve degeneration. Acta Neuropathol. Commun. 8:51. doi: 10.1186/s40478-020-00921-w

Wilkinson, D. G., Bhatt, S., Chavrier, P., Bravo, R., and Charnay, P. (1989). Segment-specific expression of a zinc-finger gene in the developing nervous system of the mouse. Nature 337, 461-464. doi: 10.1038/33 $7461 \mathrm{a} 0$

Woodhoo, A., Sahni, V., Gilson, J., Setzu, A., Franklin, R. J., Blakemore, W. F., et al. (2007). Schwann cell precursors: a favourable cell for myelin repair in the central nervous system. Brain 130, 2175-2185. doi: 10.1093/brain/ awm 125

Wu, L. M. N., Deng, Y., Wang, J., Zhao, C., Wang, J., Rao, R., et al. (2018). Programming of Schwann cells by Lats1/2-TAZ/YAP signaling drives malignant peripheral nerve sheath tumorigenesis. Cancer Cell 33, 292.e7-308.e7. doi: 10.1016/j.ccell.2018.01.005

Wu, Z., Parry, M., Hou, X.-Y., Liu, M.-H., Wang, H., Cain, R., et al. (2020). Gene therapy conversion of striatal astrocytes into GABAergic neurons in mouse models of Huntington's disease. Nat. Commun. 11:1105. doi: 10.1038/s41467020-14855-3

Yamada, Y., Trakanant, S., Nihara, J., Kudo, T., Seo, K., Saeki, M., et al. (2020). Gli3 is a key factor in the Schwann cells from both intact and injured peripheral nerves. Neuroscience 432, 229-239. doi: 10.1016/j.neuroscience.2020.02.036

Yang, D. P., Kim, J., Syed, N., Tung, Y.-J., Bhaskaran, A., Mindos, T., et al. (2012). P38 MAPK activation promotes denervated Schwann cell phenotype and functions as a negative regulator of Schwann cell differentiation and myelination. J. Neurosci. 32, 7158-7168. doi: 10.1523/JNEUROSCI.581211.2012

Yang, N., Zuchero, J. B., Ahlenius, H., Marro, S., Ng, Y. H., Vierbuchen, T., et al. (2013). Generation of oligodendroglial cells by direct lineage conversion. Nat. Biotechnol. 31, 434-439. doi: 10.1038/nbt.2564

Yang, S. H., Sharrocks, A. D., and Whitmarsh, A. J. (2013). MAP kinase signalling cascades and transcriptional regulation. Gene 513, 1-13. doi: 10.1016/j.gene. 2012.10.033

Yu, W.-M., Yu, H., Chen, Z.-L., and Strickland, S. (2009). Disruption of laminin in the peripheral nervous system impedes nonmyelinating Schwann cell development and impairs nociceptive sensory function. Glia 57, 850-859. doi: 10.1002/glia.20811

Yu, Y., Chen, Y., Kim, B., Wang, H., Zhao, C., He, X., et al. (2013). Olig2 targets chromatin remodelers to enhancers to initiate oligodendrocyte differentiation. Cell 152, 248-261. doi: 10.1016/j.cell.2012.12.006

Zakrzewski, W., Dobrzynski, M., Szymonowicz, M., and Rybak, Z. (2019). Stem cells: past, present and future. Stem Cell Res. Ther. 10:68. doi: 10.1186/s13287019-1165-5

Zanazzi, G., Einheber, S., Westreich, R., Hannocks, M. J., Bedell-Hogan, D., Marchionni, M. A., et al. (2001). Glial growth factor/neuregulin inhibits Schwann cell myelination and induces demyelination. J. Cell Biol. 152, 1289-1299. doi: 10.1083/jcb.152.6.1289

Zaret, K. S., and Mango, S. E. (2016). Pioneer transcription factors, chromatin dynamics and cell fate control. Curr. Opin. Genet. Dev. 37, 76-81. doi: 10.1016/j. gde.2015.12.003

Zhai, Q., Wang, J., Kim, A., Liu, Q., Watts, R., Hoopfer, E., et al. (2003). Involvement of the ubiquitin-proteasome system in the early stages of wallerian degeneration. Neuron 39, 217-225. doi: 10.1016/s0896-6273(03) 00429-x

Zhou, Q., Brown, J., Kanarek, A., Rajagopal, J., and Melton, D. A. (2008). In vivo reprogramming of adult pancreatic exocrine cells to beta-cells. Nature 455 , 627-632. doi: 10.1038/nature07314

Zhou, Q., Wang, S., and Anderson, D. J. (2000). Identification of a novel family of oligodendrocyte lineage-specific basic helix-loop-helix transcription factors. Neuron 25, 331-343. doi: 10.1016/s0896-6273(00) 80898-3

Zhou, X.-H., Ning, G.-Z., Feng, S.-Q., Kong, X.-H., Chen, J.-T., Zheng, Y.-F., et al. (2012). Transplantation of autologous activated Schwann cells in the treatment of spinal cord injury: six cases, more than 5 years of follow-up. Cell Transplant. 21, S39-S47. doi: 10.3727/096368912X633752

Ziegler, L., Grigoryan, S., Yang, I. H., Thakor, N. V., and Goldstein, R. S. (2011). Efficient generation of Schwann cells from human embryonic stem cell-derived neurospheres. Stem Cell Rev. Rep. 7, 394-403. doi: 10.1007/s12015-0109198-2

Zorick, T. S., Syroid, D. E., Arroyo, E., Scherer, S. S., and Lemke, G. (1996). The transcription factors SCIP and Krox-20 mark distinct stages and cell fates in Schwann cell differentiation. Mol. Cell. Neurosci. 8, 129-145. doi: 10.1006/mcne.1996.0052

Zorick, T. S., Syroid, D. E., Brown, A., Gridley, T., and Lemke, G. (1999). Krox20 controls SCIP expression, cell cycle exit and susceptibility to apoptosis in developing myelinating Schwann cells. Development 126, 1397-1406.

Zujovic, V., Thibaud, J., Bachelin, C., Vidal, M., Deboux, C., Coulpier, F., et al. (2011). Boundary cap cells are peripheral nervous system stem cells that can be redirected into central nervous system lineages. Proc. Natl. Acad. Sci. US A 108, 10714-10719. doi: 10.1073/pnas.1018687108

Conflict of Interest: The authors declare that the research was conducted in the absence of any commercial or financial relationships that could be construed as a potential conflict of interest.

Copyright (C) 2021 Balakrishnan, Belfiore, Chu, Fleming, Midha, Biernaskie and Schuurmans. This is an open-access article distributed under the terms of the Creative Commons Attribution License (CC BY). The use, distribution or reproduction in other forums is permitted, provided the original author(s) and the copyright owner(s) are credited and that the original publication in this journal is cited, in accordance with accepted academic practice. No use, distribution or reproduction is permitted which does not comply with these terms. 